\title{
Vapour pressure and vaporization heat of molecules that associate in the gas phase
}

\author{
Radomir I. Slavchov ${ }^{1}$, Javor K. Novev ${ }^{2}$, Sebastian Mosbach ${ }^{1}$, Markus Kraft ${ }^{1,3}$ \\ ${ }^{1}$ Department of Chemical Engineering, University of Cambridge, UK \\ ${ }^{2}$ Department of Chemistry, Physical and Theoretical Chemistry Laboratory, University of \\ Oxford, UK \\ ${ }^{2}$ School of Chemical and Biomedical Engineering, Nanyang Technological University, \\ Singapore \\ E-mail: ris26@cam.ac.uk
}

\begin{abstract}
A model of the temperature dependence of the vapour pressure and the heat of vaporization of associated liquids whose vapours contain associates is presented for two cases: dimers and linear associates in the gas phase. The results are analytic generalizations of the Clausius-Clapeyron equation, valid with accuracy of $0.1-1 \%$, as demonstrated with 11 liquids: formic and acetic acids, methanol, ethanol, $n$-propanol, $n$-butanol, water, benzene, toluene, heptane, and isooctane. The model involves only readily available handbook parameters: the room-temperature vaporization heat, vapour pressure, heat capacities, $2^{\text {nd }}$ virial coefficient, and heat of dissociation of the dimers in the gas phase.
\end{abstract}

Keywords: vapour pressure, Clausius-Clapeyron equation, dimerization, hydrogen bond, carboxylic acid, virial coefficient 


\section{Introduction}

The vapour pressure $p$ of a single-component liquid is a well-understood quantity ${ }^{1}$. The knowledge of two standard thermodynamic parameters, the heat of evaporation $\Delta_{\mathrm{v}} H$ and the normal boiling temperature, already allows the prediction of $p$ with decent accuracy through the Clausius-Clapeyron equation, at least far from the critical point. Better accuracy can be achieved $^{1-6}$ by accounting for the fugacity coefficient of the gas and the detailed temperature dependence of $\Delta_{\mathrm{v}} H$, but at the expense of simplicity. For this reason, the most widely used equations for the vapour pressure in everyday engineering are empirical, such as the Antoine equation ${ }^{7,8}$ and many others ${ }^{1}$ that involve parameters with unclear physical meaning. The validity of the empirical equations is limited by the accuracy of the experimental data behind them, and they hold only within the experimental temperature range; they cannot be used for extrapolation outside this range.

In this work, we evaluate two models of the vapour pressure of a class of single-component systems - liquids with a significant level of associate formation in the gas phase. Common substances such as carboxylic acids and $\mathrm{NO}_{2}$ have a significant degree of dimerization in the vapour phase; short-chained fatty alcohols form linear associates, and within a wide vapour pressure interval, the same approximation can be used for the vapours of water, amines, a variety of hydrocarbons, mercury, and many more. The models presented here combine accuracy with simplicity, and involve only standard thermodynamic quantities that can be found in many handbooks. They allow also the accurate prediction of the vaporization heat.

\section{Theory}

Let the vapour be an ideal gas mixture of monomers $\mathrm{A}$ and dimers $\mathrm{A}_{2}$. A dimerization equilibrium is established in the gas phase:

$$
\mathrm{A}_{2} \stackrel{K_{\mathrm{d}}}{\rightleftarrows} 2 \mathrm{~A} ; \quad K_{\mathrm{d}}=p_{1}^{2} / p_{2}
$$

where $p_{1}$ and $p_{2}$ are partial pressures of the monomer and the dimer, and $K_{\mathrm{d}}$ is the dissociation constant (cf. S8 for a list of symbols). The equation of state of such a gas is obtained ${ }^{9}$ by solving the mass balance $1 / V_{\mathrm{m}}^{\mathrm{g}}=p_{1} / R T+2 p_{2} / R T$, Dalton's law $p=p_{1}+p_{2}$, and the equilibrium condition (1) for $p_{1}, p_{2}$, and $V_{\mathrm{m}}^{\mathrm{g}}$ (the molar volume defined with respect to the total number of molecules in the gas phase, contained in both monomers and dimers); the result for $V_{\mathrm{m}}^{\mathrm{g}}$ reads

$$
V_{\mathrm{m}}^{\mathrm{g}}=\frac{R T}{2 p}\left[1+\left(1+4 p / K_{\mathrm{d}}\right)^{-1 / 2}\right] \text {. }
$$

This constitutive relation has been derived many times in various forms ${ }^{9-11}$, but is due to Gibbs $^{12}$. In the limit of weakly dimerized gas $\left(p<<K_{\mathrm{d}}\right)$, it simplifies to the virial expansion:

$$
V_{\mathrm{m}}^{\mathrm{g}} \stackrel{p \rightarrow 0}{\longrightarrow} \frac{R T}{p}-\frac{R T}{K_{\mathrm{d}}} \ldots
$$

In general, a description of imperfect gases based on molecular associates or clusters (such as ours) is fully equivalent to the virial expansion ${ }^{13}$, and a rigorous definition of associate can be given based on this equivalency (some useful theoretical results are summarized in S1). In the other limit of completely dimerized gas $\left(p>K_{\mathrm{d}}\right.$ ), Eq (2) yields $V_{\mathrm{m}}^{\mathrm{g}}=R T / 2 p$, reflecting that in such a gas the molar volume $V_{\mathrm{m} 2}^{\mathrm{g}}$ per dimer is twice that per molecule $\left(V_{\mathrm{m} 2}^{\mathrm{g}}=2 V_{\mathrm{m}}^{\mathrm{g}}\right)$. The fugacity $f$ of the vapour follows ${ }^{14,15}$ from the integration of the fundamental equation $R T(\partial \ln f / \partial p)_{T}=V_{\mathrm{m}}^{\mathrm{g}}$, 


$$
f=p \exp \int_{0}^{p}\left(\frac{V_{\mathrm{m}}^{\mathrm{g}}}{R T}-\frac{1}{p}\right) \mathrm{d} p=K_{\mathrm{d}} y, \text { where } y=\frac{1}{2}\left(\sqrt{1+4 p / K_{\mathrm{d}}}-1\right) .
$$

The physical meaning of $y$ is molar/pressure ratio between dimers and monomers, $y \equiv p_{2} / p_{1}$. The relation $f=p_{1}$ holds, as required by the general theory of associated solutions ${ }^{14,15}$. The weight fractions $w_{1}$ of molecules in monomers and $w_{2}$ in dimers are given by

$$
w_{1}=1 /(1+2 y)=\left(1+4 p / K_{\mathrm{d}}\right)^{-1 / 2} ; \quad w_{2}=1-w_{1} .
$$

Using these, one can write $\mathrm{Eq}(2)$ in the more transparent form $V_{\mathrm{m}}^{\mathrm{g}}=w_{1} R T / p+w_{2} R T / 2 p$.

The dissociation constant $K_{\mathrm{d}}$ is a function of the temperature. It can be determined directly from $p-V_{\mathrm{m}}^{\mathrm{g}}-T$ data by solving Eq (2) for $K_{\mathrm{d}}$ (cf. S2). A second option is to use virial coefficient data - the expansion in series (3) shows that $K_{\mathrm{d}}$ is related to $B$ as

$$
K_{\mathrm{d}}=-R T / B \text {. }
$$

This relation can be derived alternatively by introducing an appropriate definition of "dimer", cf. S1. The van 't Hoff equation can be utilized to relate $K_{\mathrm{d}}(T)$ to the dissociation heat $\Delta_{\mathrm{d}} H$ :

$$
\frac{\mathrm{d} \ln K_{\mathrm{d}}(T)}{\mathrm{d} T}=\frac{\Delta_{\mathrm{d}} H(T)}{R T^{2}}, \quad K_{\mathrm{d}}(T)=K_{\mathrm{d}}^{\ominus} \exp \int_{T^{\odot}}^{T} \frac{\Delta_{\mathrm{d}} H(T)}{R T^{2}} \mathrm{~d} T ;
$$

here, $T^{\ominus}$ is $25^{\circ} \mathrm{C}$, and $K_{\mathrm{d}}^{\ominus}$ is the dissociation constant at $T^{\ominus}$.

The vaporization heat $\Delta_{\mathrm{v}} H$ for dimerizing vapours depends on the degree of dissociation of the vapour, as it follows from the Gibbs-Helmholtz equation:

$$
\Delta_{\mathrm{v}} H=-T^{2} \frac{\partial}{\partial T} \frac{\mu^{\mathrm{g}}-\mu^{1}}{T}=\Delta_{\mathrm{v}} H_{1}-\frac{R T^{2}}{f} \frac{\partial f}{\partial T}=\Delta_{\mathrm{v}} H_{1}-w_{2} \frac{\Delta_{\mathrm{d}} H}{2} ;
$$

here, $\mu^{\mathrm{g}}$ and $\mu^{\mathrm{l}}$ are the chemical potentials of the gas and the liquid, and $\mu^{\mathrm{g}}=\mu^{\ominus}+R T \ln f ; w_{2}$ is the weight fraction from Eq (5) (which leads to a dependence of $\Delta_{\mathrm{v}} H$ on the pressure); $\Delta_{\mathrm{v}} H_{1}$ is the heat of evaporation of the monomer, and $\Delta_{\mathrm{v}} H_{1}$ and $\mu^{\ominus}-\mu^{\mathrm{l}}$ are related through another GibbsHelmholtz equation. In the derivation of $\mathrm{Eq}(8)$, formula (4) has been used for $f$ together with van 't Hoff's relation (7) for $K_{\mathrm{d}}$. The result (8) reflects Hess's law: the evaporation heat $\Delta_{\mathrm{v}} H$ is the sum of the heats $\Delta_{\mathrm{v}} H_{1}$ for evaporating monomers and $-w_{2} \Delta_{\mathrm{d}} H / 2$ released from the dimerization of a fraction $w_{2}$ of them ${ }^{11}$.

The vapour pressure p for dimerizing vapours is the solution to Clapeyron's equation,

$$
\frac{\mathrm{d} p}{\mathrm{~d} T}=\frac{\Delta_{\mathrm{v}} H}{T V_{\mathrm{m}}^{\mathrm{g}}\left(1-V_{\mathrm{m}}^{1} / V_{\mathrm{m}}^{\mathrm{g}}\right)},
$$

where $V_{\mathrm{m}}^{1}$ is the molar volume of the liquid. For the liquids considered below, $V_{\mathrm{m}}^{1} / V_{\mathrm{m}}^{\mathrm{g}}$ can be neglected. For example, for acetic acid at $140{ }^{\circ} \mathrm{C}, V_{\mathrm{m}}^{1} / V_{\mathrm{m}}^{\mathrm{g}}=0.5 \%$ so setting $1-V_{\mathrm{m}}^{\mathrm{l}} / V_{\mathrm{m}}^{\mathrm{g}}$ equal to one results in error in $p$ of the order of $0.5 \%$. As the available vapour pressure experiments for $\mathrm{CH}_{3} \mathrm{COOH}$ are of similar or lower accuracy, this is a reasonable approximation. Substituting Eqs (2),(8) and (5) in (9), $V_{\mathrm{m}}^{1}$ being neglected, and using the relations (7) and $p=K_{\mathrm{d}} y(1+y)$ following from (4), one obtains the following form of the Clausius-Clapeyron equation valid for dimerizing vapours:

$$
\frac{\mathrm{d} \ln y}{\mathrm{~d} T}=\frac{\Delta_{\mathrm{v}} H_{1}-\Delta_{\mathrm{d}} H}{R T^{2}},
$$

which integrates to

$$
\ln \frac{y}{y^{\star}}=\int_{T^{*}}^{T} \frac{\Delta_{\mathrm{v}} H_{1}-\Delta_{\mathrm{d}} H}{R T^{2}} \mathrm{~d} T .
$$

Here, $y^{\ominus}$ stands for 


$$
y^{\ominus}=\frac{1}{2}\left(\sqrt{1+4 p^{\ominus} / K_{\mathrm{d}}^{\ominus}}-1\right),
$$

where $p^{\ominus}$ is the vapour pressure at $25{ }^{\circ} \mathrm{C}$. We assume that the linear dependence $\Delta_{\mathrm{v}} H_{1}=\Delta_{\mathrm{v}} H^{\ominus}$ $+\Delta_{\mathrm{v}} C_{1}\left(T-T^{\ominus}\right)$ holds for the heat of evaporation of monomers, with $\Delta_{\mathrm{v}} H^{\ominus} \equiv \Delta_{\mathrm{v}} H_{1}\left(T^{\ominus}\right)$ being the enthalpy change for the vaporization process under standard conditions; $\Delta_{\mathrm{v}} C_{1}=C_{1}^{\mathrm{g}}-C_{\mathrm{m}}^{1}$, where $C_{1}^{\mathrm{g}}$ is the partial molar heat capacity of the monomer at constant pressure and $C_{\mathrm{m}}^{1}$ is the molar capacity of the liquid (the dependence of the enthalpy of the liquid on pressure is neglected, an approximation that holds within an error of $\mathrm{O}\left(V_{\mathrm{m}}^{1} / V_{\mathrm{m}}^{\mathrm{g}}\right)$ in the result for $\left.p\right)$. Similarly, we use $\Delta_{\mathrm{d}} H=\Delta_{\mathrm{d}} H^{\ominus}+\Delta_{\mathrm{d}} C\left(T-T^{\ominus}\right)$ for the enthalpy of dimer dissociation, Eq (1), where $\Delta_{\mathrm{d}} H^{\ominus} \equiv \Delta_{\mathrm{d}} H\left(T^{\ominus}\right) ; \Delta_{\mathrm{d}} C=2 C_{1}^{\mathrm{g}}-C_{2}^{\mathrm{g}}$ is the change of constant-pressure heat capacity upon dimerization, with $C_{2}^{\mathrm{g}}$ denoting the partial molar heat capacity of the dimer. Using these assumptions, one obtains from (11) the explicit formula

$$
y=y^{\diamond}\left(\frac{T}{T^{\oplus}}\right)^{\frac{\Delta_{\mathrm{V}} C_{1}-\Delta_{\mathrm{d}} C}{R}} \exp \left[-\frac{\Delta_{\mathrm{v}} H_{1}^{\diamond}-\Delta_{\mathrm{d}} H^{\star}-T^{\bullet}\left(\Delta_{\mathrm{v}} C_{1}-\Delta_{\mathrm{d}} C\right)}{R}\left(\frac{1}{T}-\frac{1}{T^{\odot}}\right)\right] .
$$

The temperature dependence of the dissociation constant $K_{\mathrm{d}}$ that corresponds to the linear $\Delta_{\mathrm{d}} H(T)$ follows from $\mathrm{Eq}(7)$ :

$$
K_{\mathrm{d}}(T)=K_{\mathrm{d}}^{\ominus}\left(\frac{T}{T^{\ominus}}\right)^{\Delta_{\mathrm{d}} C / R} \exp \left[-\frac{\Delta_{\mathrm{d}} H^{\ominus}-T^{\ominus} \Delta_{\mathrm{d}} C}{R}\left(\frac{1}{T}-\frac{1}{T^{\ominus}}\right)\right] ;
$$

this is Kirchhoff's equation for $K_{\mathrm{d}}$. The vapour pressure is related to the pressure fraction $y$ as $p=K_{\mathrm{d}} y(1+y)$, which leads to the final result:

$$
\frac{p}{[p]}=\left(\frac{T}{T^{\ominus}}\right)^{\Delta_{\mathrm{v}} C_{1} / R} \mathrm{e}^{A_{1}-E_{1} / R T}+\left(\frac{T}{T^{\ominus}}\right)^{\Delta_{\mathrm{v}} C_{2} / R} \mathrm{e}^{A_{2}-E_{2} / R T},
$$

where $\Delta_{\mathrm{v}} C_{2} \equiv 2 \Delta_{\mathrm{v}} C_{1}-\Delta_{\mathrm{d}} C=C_{2}^{\mathrm{g}}-2 C_{\mathrm{m}}^{1},[p]$ are the units of pressure, and the 4 parameters $A$ and $E$ are related to the thermodynamic parameters of the liquid and the gas:

$$
\begin{gathered}
E_{1}=\Delta_{\mathrm{v}} H_{1}^{\diamond}-T^{\diamond} \Delta_{\mathrm{v}} C_{1}, \quad E_{2}=2 E_{1}-\Delta_{\mathrm{d}} H^{\diamond}+T^{\diamond} \Delta_{\mathrm{d}} C ; \\
A_{1}=\ln \frac{y^{\diamond} K_{\mathrm{d}}^{\diamond}}{[p]}+\frac{E_{1}}{R T^{\diamond}}, \quad A_{2}=\ln \frac{K_{\mathrm{d}} y^{\bullet 2}}{[p]}+\frac{E_{2}}{R T^{\ominus}} .
\end{gathered}
$$

The result (15) can be called Kirchhoff's equation for the pressure of dimerizing vapours, generalizing Kirchhoff's equation for the vapour pressure when the gas phase is ideal, see Reid et al. ${ }^{1}, p .174$, as well as Dake ${ }^{4}$. The two addends in Eq (15) are in fact the partial pressures of the monomers and the dimers. For most practical purposes, where the degree of association is less than $10 \%$, the capacity $\Delta_{\mathrm{d}} C$ can be set to 0 as it does not affect $p$ significantly. For a liquid for which $\Delta_{\mathrm{v}} H^{\ominus}, p^{\ominus}, \Delta_{\mathrm{v}} C_{1}, K_{\mathrm{d}}^{\ominus}, \Delta_{\mathrm{d}} H^{\ominus}$ and $\Delta_{\mathrm{d}} C$ are known with high precision, the vapour pressure can be predicted via Eq (15) with accuracy that outmatches the one of, e.g., the Antoine equation; in addition, the model allows the fraction of dimers in the gas phase to be calculated via $\mathrm{Eq}(5)$, and the vaporization heat - via Eq (8).

Let us now examine the case with "linear" associates $\mathrm{A}_{n}$ of arbitrary size $n=[1, \infty)$. We will consider the dissociation process

$$
\mathrm{A}_{n} \stackrel{K_{\mathrm{d}}}{\rightleftarrows} \mathrm{A}+\mathrm{A}_{n-1} \text {, where } \quad K_{\mathrm{d}}=p_{1} p_{n-1} / p_{n} ;
$$

we will assume that the dissociation constant $K_{\mathrm{d}}$ is independent of $n$ (a model used often for solutions of alcohols in non-polar liquids [EW Lassettre, JACS 59 (1937) 1383 - freezing point HC solutions; H Kempter, R. Mecke, Naturwiss. 27 (1939) 583; Prigogine's book]). This assumption usually underestimates the stability of the trimers, as discussed in S1. Following 
the same line of reasoning as above, we obtain the following equation for the heat of evaporation for vapours forming linear associates:

$$
\Delta_{\mathrm{v}} H=\Delta_{\mathrm{v}} H_{1}-\frac{R T^{2}}{f} \frac{\partial f}{\partial T}=\Delta_{\mathrm{v}} H_{1}-y \Delta_{\mathrm{d}} H, \text { with } y=\frac{p}{p+K_{\mathrm{d}}} .
$$

We have used that, since $K_{\mathrm{d}}$ for all dissociation steps are equivalent, the respective dissociation enthalpies $\Delta_{\mathrm{d}} H$ are also equal. The factor $y$ is equal to $\Sigma(i-1) w_{i} / i$ and stands for the average number of bonds per molecule in the associated vapours. The quantity $y$ is analogous to the one for dimers in $\mathrm{Eq}(4)$ : the relations $f=K_{\mathrm{d}} y$ and $y=p_{2} / p_{1}$ still hold true for the case of linear associates, see S1. In addition, the form (10) of the Clausius-Clapeyron equation is still valid, and so is its solution (13), but with a different $y^{\ominus}$ :

$$
y^{\ominus}=\frac{p^{\ominus}}{p^{\ominus}+K_{\mathrm{d}}^{\ominus}} .
$$

The end result for the vapour pressure for vapours forming linear associates is obtained as $p=K_{\mathrm{d}} y /(1-y)$ following from Eq (18), and Eqs (13) and (14):

$$
p=\left[\frac{1}{\left(T / T^{\ominus}\right)^{\Delta_{v} C_{1} / R} \mathrm{e}^{A_{1}-E_{1} / R T}}-\frac{1}{K_{\mathrm{d}}}\right]^{-1} .
$$

This result can be called Kirchhoff's equation for the pressure of vapours forming linear associates. Here, $K_{\mathrm{d}}$ is given by Kirchhoff's Eq (14), and $A_{1}$ and $E_{1}$ are given by Eqs (16), but this time $y^{\ominus}$ stands for the expression (19).

Since the trimers (and the higher associates) are usually more stable than what follows from the assumption $K_{\mathrm{d} 3}=K_{\mathrm{d} 2}$, Eq (18) and (20) can be expected to be only moderately improved compared to their analogues for pure dimerization, Eqs (8) and (15); both models will fail at pressures and temperatures at which aggregates of size $n \geq 3$ are significant. A better approach to associating gases would use, in principle, $K_{\mathrm{d} 3}$ determined from data for the $3^{\text {rd }}$ virial coefficient. Unfortunately, we find the published collections of $3^{\text {rd }}$ virial coefficients extremely unreliable, especially for polar gases (an example is given in S2), which makes the effort futile.

\section{Comparison with experiment}

The vapours of formic and acetic acid are classical examples for strong dimerization, and generations of scientists have studied the effect of the dimers on their physicochemical properties $^{12,16}$. Several complications lead to discordant results for all relevant experimental quantities $\left(p-V_{\mathrm{m}}^{\mathrm{g}}-T\right.$ data, vapour pressure, $\left.\Delta_{\mathrm{v}} H\right)$ - these are: (i) tendency for adsorption of the acid at the walls of the container ${ }^{17}$; (ii) tendency to decompose to $\mathrm{CO}$ and $\mathrm{H}_{2} \mathrm{O}^{18}$; (iii) water impurities $^{19,20}$; (iv) slow kinetics of equilibration between the monomers and the dimers ${ }^{21}$. In confirmation of the last point, Faubel and Kisters ${ }^{22}$ found the evaporative flux carries strongly non-equilibrated mixture of monomers and dimers: what vaporizes from the surface at $252 \mathrm{~K}$ is a mixture of $70 \%$ monomers and $30 \%$ dimers, while the equilibrium fraction of dimers is approximately $w_{2}=96 \%$ at this temperature; in addition, the average kinetic energy of the dimers is higher than that of the monomers, corresponding to an effective difference in temperature of $100-200 \mathrm{~K}^{22}$. The existence of trimers and tetramers has been postulated ${ }^{23}$, and later rejected ${ }^{16}$; the analysis in $\mathrm{S} 2$ confirms that only dimers exist in appreciable amounts in the acid vapours. In result of these complications, the handbook values for the quantities involved in Eq (15) are not accurate enough to predict the vapour pressure with the accuracy of the available experimental data. We therefore re-determined the relevant parameters. 
Acetic acid. We obtain the temperature dependence $K_{\mathrm{d}}(T)$ of the dissociation constant of the dimer directly from the published $p-V_{\mathrm{m}}^{\mathrm{g}}-T$ data ${ }^{23-26}$, Gibbs' Table $I V^{27}$, limiting ourselves to the temperature range of 10 to $180{ }^{\circ} \mathrm{C}$ since the available vapour pressure data are within a similar interval. We use Eqs (2) and (14) to fit the $p-V_{\mathrm{m}}^{\mathrm{g}}-T$ data. The three parameters of Eq (14) are sought: $K_{\mathrm{d}}^{\ominus}, \Delta_{\mathrm{d}} H^{\ominus}$, and $\Delta_{\mathrm{d}} C$. The heat capacity change $\Delta_{\mathrm{d}} C$ is not required with high precision, so we used for it the theoretical value at $25{ }^{\circ} \mathrm{C}, \Delta_{\mathrm{d}} C=-10.37 \mathrm{~J} / \mathrm{molK}$, as it follows from the calculations of Chao and Zwolinski ${ }^{28}$. The other two parameters are determined from the regression as $K_{\mathrm{d}}^{\ominus}=60.33 \mathrm{~Pa}$ and $\Delta_{\mathrm{d}} H^{\ominus}=64.16 \mathrm{~kJ} / \mathrm{mol}$; the average difference between the experimental and computed $V_{\mathrm{m}}^{\mathrm{g}}$ values is $1.4 \%$, similar to the discrepancy between the data sets of the different authors (cf. Figure S1 in S2). Our values can be compared to the theoretical ones, $K_{\mathrm{d}}^{\ominus}=79.2 \mathrm{~Pa}$ and $\Delta_{\mathrm{d}} H^{\ominus}=63.2 \mathrm{~kJ} / \mathrm{mol}$, that follow from Ref. $\left[{ }^{28}\right]$; the latter correspond to a deviation of $2.3 \%$ from the experimental $p-V_{\mathrm{m}}^{\mathrm{g}}-T$ (much higher than the one with our values). Comparison with data for the $2^{\text {nd }}$ virial coefficient $B$ is made in $\mathrm{S} 2$; the $3^{\text {rd }}$ virial coefficient is also discussed there.

We further compare Eq (15) to vapour pressure data from various authors ${ }^{29-33}$ in the range $T=[25,142]{ }^{\circ} \mathrm{C}$ and $p=[2,200] \mathrm{kPa}$, to determine the values of $p^{\ominus}, \Delta_{\mathrm{v}} H^{\ominus}$, and $\Delta_{\mathrm{v}} C_{1}$ given in Table 1 (cf. S2 for details about the procedure). The average deviation from the experiment is $0.3 \%$; the dispersion is most significant in the low-temperature region where the data from the different authors deviate from one another (Figure S3). The best-fit $p^{\ominus}=2.0706 \mathrm{kPa}$ from our regression analysis compares well to $2.08 \mathrm{kPa}$ cited by Marcus ${ }^{34}$, within the precision of his value, and $\Delta_{\mathrm{v}} H^{\ominus}=52.380 \mathrm{~kJ} / \mathrm{mol}$ agrees with $52.1 \mathrm{~kJ} / \mathrm{mol}$ from the CRC Handbook ${ }^{35}$ - however, the 3 valid digits of the handbook values are insufficient to calculate the vapour pressure with the experimental precision. From our fitted value of $\Delta_{\mathrm{v}} C_{1}=-47.26 \mathrm{~J} / \mathrm{molK}$ and the heat capacity of the liquid, $C_{\mathrm{m}}^{1}=123.3 \mathrm{~J} / \mathrm{molK}^{34,35}$, the capacity of the monomer follows, $C_{1}^{\mathrm{g}}=C_{\mathrm{m}}^{1}+\Delta_{\mathrm{v}} C_{1}=$ $76.0 \mathrm{~J} / \mathrm{molK}$. Chao and Zwolinski ${ }^{28}$ calculated that $C_{1}^{\mathrm{g}}$ varies from 63.4 to $94 \mathrm{~J} / \mathrm{molK}$ in the interval $[300,500] \mathrm{K}$; thus, the fitted $\Delta_{\mathrm{V}} C_{1}$ value evidently corresponds to an average. The temperature dependence of $\Delta_{\mathrm{V}} C_{1}$ can be accounted for easily, but it does not significantly affect the precision of the final result, so we neglect it.

We further test the parameters we obtained by calculating the heat of evaporation $\Delta_{\mathrm{v}} H$ via $\mathrm{Eq}$ (8). The result at $25^{\circ} \mathrm{C}$ is $23.03 \mathrm{~kJ} / \mathrm{mol}$, within $0.1 \%$ from the value $23.00 \mathrm{~kJ} / \mathrm{mol}$ in Marcus's book $^{34}$; at $117.4{ }^{\circ} \mathrm{C}$, we calculate 24.28 , comparing well with Brown's ${ }^{36}$ experimental 24.38 $\mathrm{kJ} / \mathrm{mol}$. The second test consists in calculating the normal boiling temperature by solving the equation $p(T)=101325 \mathrm{~Pa}$, where $p$ is given by (15). The result is $117.89{ }^{\circ} \mathrm{C}$, compared to $117.85-117.9^{\circ} \mathrm{C}^{34,35}$.

Formic acid. The $p-V_{\mathrm{m}}^{\mathrm{g}}-T$ data ${ }^{18,24}$ in the temperature range $[10,156]{ }^{\circ} \mathrm{C}$ are used together with Eqs (2) and (14) to determine $K_{\mathrm{d}}^{\ominus}=325.1 \mathrm{~Pa}$ and $\Delta_{\mathrm{d}} H^{\ominus}=58.53 \mathrm{~kJ} / \mathrm{mol}\left(\Delta_{\mathrm{d}} C\right.$ is fixed to its theoretical ${ }^{28}$ value at $25{ }^{\circ} \mathrm{C},-4.782 \mathrm{~J} / \mathrm{molK}$ ). The average deviation between the experimental and computed $V_{\mathrm{m}}^{\mathrm{g}}$ is $0.7 \%$, approaching the experimental precision, whereas for comparison, the values of Chao and Zwolinski ${ }^{28}, K_{\mathrm{d}}^{\ominus}=282 \mathrm{~Pa}$ and $\Delta_{\mathrm{d}} H^{\ominus}=63.8 \mathrm{~kJ} / \mathrm{mol}$, correspond to a large deviation of $2.6 \%$. Comparison with handbook data for $B$ is given in Figure $S 1$.

We further simultaneously fit Eq (15) to vapour pressure data ${ }^{19,20,37}$ falling in the range $T=$ $[-5,120]{ }^{\circ} \mathrm{C}$ and $p=[1,170] \mathrm{kPa}$, and $\mathrm{Eq}(8)$ to vaporization heat data ${ }^{19,21,38}$. The parameters $p^{\ominus}=5.692 \mathrm{kPa}, \Delta_{\mathrm{v}} H^{\ominus}=45.902 \mathrm{~kJ} / \mathrm{mol}$, and $\Delta_{\mathrm{v}} C_{1}=-39.3 \mathrm{~J} / \mathrm{molK}$ are thus obtained (cf. $\mathrm{S} 2$ for details). The average deviation from the measurements is $0.5 \%$, comparable to the experimental dispersion, both for vapour pressure and $\Delta_{\mathrm{v}} H$. A 3-parametric fit over the vapour pressure data with the Antoine equation has been performed for comparison, which gives $\ln (p /[\mathrm{Pa}])=21.755$ $-3530.6 /(T /[\mathrm{K}]-28.85)$, and the average deviation is inferior, $0.6 \%$. Our value of $p^{\ominus}$ agrees 
with $5.75 \mathrm{kPa}$ cited by Marcus ${ }^{34}$, but $\Delta_{\mathrm{v}} H^{\ominus}=46.3 \mathrm{~kJ} / \mathrm{mol}$ from the CRC Handbook ${ }^{35}$ is too high. The normal boiling temperature following from $\mathrm{Eq}(15)$ is $100.86^{\circ} \mathrm{C}$, compared to the literature values $^{34,35} 100.55-101{ }^{\circ} \mathrm{C}$.

For both formic and acetic acid, the dispersion between the model and the vaporization data is very sensitive to $\Delta_{\mathrm{v}} H^{\ominus}$ : inaccuracy in the $4^{\text {th }}$ digit $(0.01 \%)$ causes a significant increase of the deviation (cf. S7 for details). The fit is also sensitive to $p^{\ominus}(0.05 \%$ change in it affects the deviation), and is only affected by inaccuracies of $1 \%$ or more in $\Delta_{v} C_{1}$. For both acids, the dissociation degree increases with $T$, due to the endothermicity of the process (1) - the weight fraction drops from more than $90 \%$ dimers at $0{ }^{\circ} \mathrm{C}$ to $w_{2}<80 \%$ above $100{ }^{\circ} \mathrm{C}$, see Figure S4right. The monomers require more energy to evaporate, so as the fraction of dimers decreases, the vaporization heat anomalously increases (Figure S4-left). At higher $T$, the vaporization heat must pass through a maximum and drop to 0 at the critical point.

The vapours of the fatty alcohols also associate to a significant degree, and unlike acids, they have a tendency to form linear associates. Polymerization in alcohol vapours has been probed experimentally and theoretically, for instance by Kell and McLaurin ${ }^{39}$ who analysed $p$ $V_{\mathrm{m}}^{\mathrm{g}}-T$ data of methanol vapours; and by Tucker et al. ${ }^{40}$ who used a monomer-trimer-octamer model to interpret $p-V_{\mathrm{m}}^{\mathrm{g}}-T$, IR and NMR data in vapours and in alkane solutions. Other authors ${ }^{41}$ have asserted that only monomers, dimers and tetramers are present in the gas phase. The form of the associates has been a subject of debate - both linear and cyclical structures have been proposed $^{40}$. The associates affect the vapour pressure significantly: for the cases we study below, associates form up to $20 \%$ of the total mass of the vapours.

We use experimental data for $B$ in the range $[20,200]{ }^{\circ} \mathrm{C}$ to calculate the parameters $K_{\mathrm{d}}^{\ominus}$ and $\Delta_{\mathrm{d}} H^{\ominus}$; unfortunately, the available data are highly discordant. To minimize the problem, we use Eqs (14) and (6) to fit data for four homologues simultaneously: from methanol to butanol. This is helpful for distinguishing realistic data from artefacts: for methanol, we use all data from Refs. $\left[{ }^{35,42}\right]$; for ethanol, we employ data from Refs. $\left[{ }^{35,42},{ }^{43-45}\right]$; for propanol - from Refs. $\left.{ }^{42,46}\right]$ and for butanol - from Refs. $\left.{ }^{35,42,46}\right]$. The data for methanol and ethanol from Dymond et al. ${ }^{46}$ and for propanol from CRC were tested separately and were found to lead to $p$ and $\Delta_{\mathrm{v}} H$ that disagree with the experimental data, so we ignored them. For the fit of $B$, we assume (i) that $\Delta_{\mathrm{d}} H^{\ominus}$ is the same for all alcohols, (ii) that a linear dependence of $\ln K_{\mathrm{d}}^{\ominus}$ on the number of carbon atoms holds, and (iii) that $\Delta_{\mathrm{d}} C$ can be neglected, see SI 3 for details. The values we obtained are given in Table 2 .

Methanol. We use handbook values for all other parameters of the model, Table 2. As observed with the acids, the fit for $p$ is very sensitive to $\Delta_{\mathrm{v}} H^{\ominus}$; the CRC Handbook ${ }^{35}$ cites $\Delta_{\mathrm{v}} H^{\ominus}$ $=38.2 \mathrm{~kJ} / \mathrm{mol}$ for it, while Marcus ${ }^{34}$ gives $\Delta_{\mathrm{v}} H\left(T^{\ominus}\right)=37.43 \mathrm{~kJ} / \mathrm{mol}$, from which $\Delta_{\mathrm{v}} H^{\ominus}=37.71$ follows via $\mathrm{Eq}$ (18). Using one of these values in $\mathrm{Eq}$ (20) yields large positive deviations, and the other yields large negative deviations from the vapour pressure data assembled by Goodwin $^{47}$, of the order of 2-4\%; we found a similar tendency of Marcus ${ }^{34}$ to underestimate and the CRC Handbook ${ }^{35}$ to overestimate $\Delta_{\mathrm{v}} H^{\ominus}$ for nearly all liquids considered below. Using the average of the two values $\left(\Delta_{\mathrm{v}} H^{\ominus}=37.95 \mathrm{~kJ} / \mathrm{mol}\right)$ leads to $0.6 \%$ average error with respect to data from Refs. ${ }^{47-50}$ in the range $15-130{ }^{\circ} \mathrm{C}$ (corresponding to $10-850 \mathrm{kPa}$ ), an impressive precision for a model of no adjustable parameters. Formula (20) gives reasonably accurate results even with extrapolation well outside the interval $50-160{ }^{\circ} \mathrm{C}$ which the $B$ data for methanol cover - the predictions of Eq (20) deviate by $3.6 \%$ from Goodwin's ${ }^{47}$ experimental vapour pressures for the temperature range $[-98,-93]^{\circ} \mathrm{C}$ (comparable with the experimental dispersion in this range). The deviation can be further decreased by tuning the parameters as done with the acids, but as $0.6 \%$ accuracy is enough for most applications, we have not done so. For comparison, we fitted the data in the range $[15,130]{ }^{\circ} \mathrm{C}$ with the Antoine equation, 
obtaining $\ln (p / \mathrm{Pa})=23.343-3555.6 /(T /[\mathrm{K}]-36.80)$; this leads to $0.3 \%$ error, and nearly any similar 3-parameter formula would lead to the same error. However, as is typical of empirical formulae, extrapolation is very inaccurate - the Antoine equation has $42 \%$ error in the temperature range $[-98,-93]{ }^{\circ} \mathrm{C}$. Furthermore, $\Delta_{\mathrm{v}} H$ predicted by Eq (18) compares well to experimental data from Counsell et al. ${ }^{49}$ and Svoboda et al. ${ }^{51}$, with an average deviation of $1.5 \%$, similar to the experimental uncertainty.

Ethanol. All required parameters are taken from the same sources and dealt with in the same manner as those of methanol - cf. Table 2 and SI 3. We compare the predictions of Eq (20) with the parameters in Table 2 to vapour pressure data ${ }^{48,52-56}$; the average deviation is $0.6 \%$. We also compare $\mathrm{Eq}(18)$ to vaporization heat measurements from Counsell et al.$^{52}$ and Dong and $\mathrm{Lin}^{54}$; the deviation is again small, $0.6 \%$ - it is commensurate with the $0.2-0.4 \%$ deviation between the two $\Delta_{\mathrm{v}} H$ datasets.

$n$-Propanol and $n$-butanol. With the parameters taken from the sources used for methanol and ethanol $\left(p^{\ominus}=2.73 \mathrm{kPa}\right.$ and $\Delta_{\mathrm{v}} H^{\ominus}=47.5 \mathrm{~kJ} / \mathrm{mol}$ for propanol; $p^{\ominus}=0.82 \mathrm{kPa}$ and $\Delta_{\mathrm{v}} H^{\ominus}=52.4$ $\mathrm{kJ} / \mathrm{mol}$ for butanol ${ }^{34,35}$ ), the discrepancy between the theory and the experimental data for $p(T)^{53,55,57}$ and $\Delta_{\mathrm{v}} H(T)^{51,57}$ is relatively high. For the evaporation of propanol at $19-105{ }^{\circ} \mathrm{C}$, $\mathrm{Eq}(20)$ deviates from the vapour pressure data ${ }^{53,55,57}$ by an average of $1.6 \%$; Eq (18) deviates by $2.3 \%$ with respect to the vaporization heat data ${ }^{51,57,58}$. This is due to the low accuracy of the handbook values. Therefore, we fit the experimental data to determine $p^{\ominus}=2.83 \mathrm{kPa}$ and $\Delta_{\mathrm{v}} H^{\ominus}$ $=47.14 \mathrm{~kJ} / \mathrm{mol}$ (leading to $\operatorname{dev} p=0.7 \%$ and $\operatorname{dev} \Delta_{\mathrm{v}} H^{\ominus}=1.7 \%$ ). The discordance between the handbook values for $p^{\ominus}$ and $\Delta_{\mathrm{v}} H^{\ominus}$ and the experimental data for $p(T)^{33,53,59}$ and $\Delta_{\mathrm{v}} H(T)^{51,57}$ of butanol at $0-126{ }^{\circ} \mathrm{C}$ is even larger. If $p^{\ominus}$ and $\Delta_{\mathrm{v}} H^{\ominus}$ are obtained from a regression instead, substantially lower standard deviations are obtained, dev $p=0.59 \%$ and $\operatorname{dev} \Delta_{\mathrm{v}} H^{\ominus}=2.13 \%$, with parameter values of $p^{\ominus}=0.956 \mathrm{kPa}$ and $\Delta_{\mathrm{v}} H^{\ominus}=51.35 \mathrm{~J} / \mathrm{mol}$.

For the alcohols, in contrast to the acids, the dissociation degree of the saturated vapour decreases with the temperature $-w_{2}<5 \%$ at $0{ }^{\circ} \mathrm{C}$ and $w_{2}>15 \%$ above $100{ }^{\circ} \mathrm{C}$, Figure $\mathrm{S} 7$-right. This trend is the result of the increased vapour pressure at high temperature, causing the equilibrium (17) to favour dimers increasingly at higher $T$ in spite of the rising $K_{\mathrm{d}}$ - compare with acids, where the second effect dominates. The vaporization heat has the normal decreasing trend with the increase of temperature (see Figure S7-left). All other conditions being equal, the weight fraction of multimers decreases as a function of the number of carbons in the chain. At the boiling temperature under $p=101325 \mathrm{~Pa}$, dimers constitute several per cent of the total mass of the vapours, and the weight fraction drops by approximately an order of magnitude for each of the next two multimers. The fraction of dimers ranges from $7.7 \%$ for methanol to $6.0 \%$ for butanol, that of trimers - from $0.5 \%$ to $0.3 \%$, and that of tetramers - from $0.03 \%$ to $0.01 \%$.

Our third example is the water-steam equilibrium. We investigate the range $p<500 \mathrm{kPa}$ only, since at higher pressures the fraction of trimers (for which our model accounts only approximately, cf. S1) becomes significant. We take the values of $p^{\ominus}, \Delta_{\mathrm{v}} H^{\ominus}$ and $\Delta_{\mathrm{v}} C_{1}$ from handbook data ${ }^{34,35}$, cf. Table 2 . For the $K_{\mathrm{d}}$ parameters, we minimize the difference between the regression formula for the second virial coefficient of water of Harvey and Lemmon ${ }^{60}$ in the range $0-200{ }^{\circ} \mathrm{C}$ and $B$ from Eqs (6) and (14) to obtain $K_{\mathrm{d}}^{\ominus}, \Delta_{\mathrm{d}} H^{\ominus}$ and $\Delta_{\mathrm{d}} C$ given in Table 2 (cf. $\mathrm{S} 4$ for details). The average difference between $\mathrm{Eq}(20)$ with these parameters and the experimental vapour pressure ${ }^{61-66}$ in the range $T=[-2.5,150]{ }^{\circ} \mathrm{C}$ is $0.4 \%$; above $100{ }^{\circ} \mathrm{C}$, however, it is comparatively high, $1-2 \%,-$ cf. S4. The difference between Eq (8) and the vaporization heat data of Osborne et al. ${ }^{67,68}$ is $0.2 \%$.

For our final example, we turn to four hydrocarbons that are of practical interest as components of gasoline - the results for them will be used in a subsequent paper to investigate the evaporation of a mixture of hydrocarbons and ethanol (gasohol), and as an example for a very different nature of the associates: association of alkanes is driven by dispersion forces, and 
of arenes - of dispersion and quadrupole interactions; these are not localized to a specific chemical group and do not orient the interacting monomers as strongly as the hydrogen-bonded associates above. The linear associate model has relatively limited applicability to hydrocarbons due to their significant trimerization (see e.g. Chirico and Steele ${ }^{69}$ ), so we consider only the range of vapour pressures below $p<100-200 \mathrm{kPa}$ where the monomers and dimers dominate; this is no great limitation for practical purposes, as this range is the most relevant one with regard to applications. Details are given in S5.

Toluene. We use $B$ data ${ }^{35,42}$ in the range $[75,165]{ }^{\circ} \mathrm{C}$ to calculate $K_{\mathrm{d}}^{\ominus}$ and $\Delta_{\mathrm{d}} H^{\ominus}$. The monomer vaporization heat is an average between those in Refs $\left[{ }^{34}\right]$ and $\left[{ }^{35}\right]$, and $\Delta_{\mathrm{v}} C_{1}$ is calculated from the values of $C_{\mathrm{m}}^{1}$ from Ref. $\left[{ }^{34}\right]$ and $C_{1}^{\mathrm{g}}$ from Ref. $\left[{ }^{70}\right]$ at $25^{\circ} \mathrm{C}$. The values we find for the vapour pressure of toluene at $25{ }^{\circ} \mathrm{C}$ in the handbooks are all of accuracy too low for our aims; therefore, we determine $p^{\ominus}$ as an adjustable parameter, using vapour pressure data from Chirico and Steele ${ }^{69}$ and Goodwin ${ }^{71}$ (only the sources 14,16,18,19,22-26,30 and 33 in the latter reference are considered). The fit leads to $p^{\ominus}=3.804 \mathrm{kPa}$ and an average deviation between the data and Eq (20) of $0.34 \%$, compared to $1.5 \%$ with Marcus' value $p^{\ominus}=3.75 \mathrm{kPa}$ ${ }^{34}$. We also compare Eq (18) with vaporization heat data from Natarajan and Viswanath ${ }^{72}$; the average deviation is again satisfactory, $0.27 \%$.

Benzene. We fit $K_{\mathrm{d}}^{\ominus}$ and $\Delta_{\mathrm{d}} H^{\ominus}$ to $B$ data from the CRC Handbook ${ }^{35}$ and Kogan et al. ${ }^{42}$ in the range $[17,177]{ }^{\circ} \mathrm{C}$, setting $\Delta_{\mathrm{d}} C$ to 0 . We use handbook data ${ }^{34}$ for $p^{\ominus}$ and $\Delta_{\mathrm{v}} H^{\ominus}$ and compare the predictions of the model to experimental data for $p(T)$ form various sources ${ }^{72-75}$ in the temperature range $[11,112]^{\circ} \mathrm{C}$ and $\Delta_{\mathrm{v}} H(T)$ from Refs. $\left[{ }^{51,76}\right]$. Thus, we obtain $\operatorname{dev} p=0.9 \%$ and $\operatorname{dev} \Delta_{\mathrm{v}} H=0.7 \%$.

Heptane. We use the average between the value of $\Delta_{\mathrm{d}} H^{\ominus}$ determined from Ref. $\left[{ }^{34}\right]$ and that given by Ref. $\left[{ }^{35}\right]$ and data for $B$ data from Ref. $\left[{ }^{35}\right]$ in the range $[25,425]{ }^{\circ} \mathrm{C}$, as described in Table 2. Substituting these in Eq (20) leads to an accuracy of $0.14 \%$ compared to vapour pressure measurements from various authors ${ }^{74,75,77,78}$. Eq (18) predicts vaporization heats by $0.4 \%$ different from the experimental ones from Waddington et al. ${ }^{77}$.

Isooctane (2,2,4-Trimethylpentane). As no data for $B$ of isooctane is available to us, we use data for normal octane from the CRC Handbook ${ }^{35}$ to calculate $K_{\mathrm{d}}^{\ominus}$ and $\Delta_{\mathrm{d}} H^{\ominus}$. The other parameters are taken from handbooks as described in Table 2. Substituting these in Eq (20) leads to accuracy of $0.7 \%$ compared to vapour pressure data from Willingham et al. ${ }^{74}$. This is acceptable accuracy, in view of the gross approximation for $B$.

A sample Maple code for the calculation of the vapour pressure, the vaporization heat and the dimerization degree using the full set of handbook parameters is given in S6.

\section{Discussion}

Our work revisits two old models of a non-ideal gas: the largely forgotten model of Gibbs for dimerizing gases ${ }^{12}$ and the model for linear associates popular for alcohols in non-polar solution [EW Lassettre, JACS 59 (1937) 1383 - freezing point HC solutions; H Kempter, R. Mecke, Naturwiss. 27 (1939) 583; Prigogine's book; doi:10.1016/j.molliq.2009.02.005] but not tested for gas phase. We demonstrate the capabilities of two direct consequences of these models: the formulae for the vapour pressure and the vaporization heat of associating compounds. With most of the liquids for which we tested it, the precision of the model is equal to the precision of the most accurate experimental data we have 140 years later, and the simplicity of the final results is remarkable. The models allow readily available handbook data to be used to predict $p$ and $\Delta_{\mathrm{v}} H$ in a vast range of temperatures and pressures. 
The usefulness of the model and the formulas (15) and (8) for dimers and (18) and (20) for linear associates will become evident as the concept is extended to (i) the problem for the kinetics of evaporation (with contribution from the dimer evaporation, the role of which has been under investigation in the last decades ${ }^{22,79}$ ); (ii) the problem for the vapour pressure of mixtures with association in the gas phase (which has been considered in some detail already ${ }^{11}$ ) - unlike the empirical models and the established detailed theories for the vapour pressure of single-component liquids, the model considered in this work is straightforward to generalize to these more complicated cases.

The limitations of the models are: (i) the neglected dependence of the heat capacity $\Delta_{\mathrm{V}} C$ on the temperature; (ii) the neglected molar volume $V_{\mathrm{m}}^{1}$ in $\mathrm{Eq}(9)$, in the pressure dependence of the enthalpy of the liquid, and the related contribution of the van der Waals repulsion to the $2^{\text {nd }}$ virial coefficient; (iii) the crude approximation for $K_{\mathrm{d}}$ independent of $n$ for the linear association model, and the neglected trimerization in the dimer model. The approximations (i) and (ii) are relatively easy to overcome, but they start to play a role at conditions where (iii) fails as well, and (iii) requires much more effort (cf. S1 for additional discussion). 
Table 1: Parameters of Kirchhoff's equation(15) for the pressure of dimerizing vapours of formic and acetic acids.

\begin{tabular}{|c|c|c|c|c|c|c|c|c|c|c|c|c|c|c|}
\hline $\begin{array}{l}\text { compound } \\
\text { range }\end{array}$ & $\begin{array}{c}p^{\ominus} \\
\mathrm{kPa}\end{array}$ & $\begin{array}{c}\Delta_{\mathrm{v}} H^{\ominus} \mathrm{kJ} / \\
\mathrm{mol}\end{array}$ & $\begin{array}{c}\Delta_{\mathrm{V}} C_{1} \\
\mathrm{~J} / \mathrm{molK}\end{array}$ & $\begin{array}{l}\ln K_{\mathrm{d}}^{\ominus} \\
/[\mathrm{Pa}]\end{array}$ & $\begin{array}{c}\Delta_{\mathrm{d}} H^{\ominus} \\
\mathrm{kJ} / \mathrm{mol}\end{array}$ & $\begin{array}{c}\Delta_{\mathrm{d}} C \\
\mathrm{~J} / \mathrm{molK}\end{array}$ & $\begin{array}{c}A_{1} \\
\text { c }\end{array}$ & $\begin{array}{c}E_{1} \\
\mathrm{~kJ} / \mathrm{mol}^{\mathrm{c}}\end{array}$ & $\begin{array}{c}A_{2} \\
\mathbf{c}\end{array}$ & $\begin{array}{c}E_{2} \\
\mathrm{~kJ} / \mathrm{mol}^{\mathrm{c}}\end{array}$ & $\underset{\mathbf{d}}{\operatorname{dev} p}$ & $\underset{\mathbf{d}}{\operatorname{dev}_{\mathrm{v}} H}$ & $\begin{array}{l}\Delta_{\mathrm{v}} H\left(T^{\ominus}\right) \\
\mathrm{kJ} / \mathrm{mol}^{\mathrm{e}}\end{array}$ & $\begin{array}{l}T_{\mathrm{b}} \\
{ }^{\circ} \mathrm{C}^{\mathrm{f}}\end{array}$ \\
\hline $\begin{array}{c}\text { HCOOH } \\
{[-5,120]{ }^{\circ} \mathrm{C},} \\
{[1,170] \mathrm{kPa}}\end{array}$ & $\begin{array}{c}5.69_{23} \\
\mathrm{a}\end{array}$ & $\begin{array}{c}45.90_{2} \\
\text { a }\end{array}$ & $\begin{array}{c}-39.3_{4} \\
\mathbf{a}\end{array}$ & $\begin{array}{c}5.78_{42} \\
\text { b }\end{array}$ & $\begin{array}{c}58.5_{33} \\
\text { b }\end{array}$ & $\begin{array}{c}-4.782 \\
28\end{array}$ & $30.34_{4}$ & $57.63_{1}$ & $30.71_{7}$ & $55.30_{3}$ & $0.5 \%$ & $0.6 \%$ & $20.10_{8}$ & 100.86 \\
\hline $\begin{array}{c}\mathrm{CH}_{3} \mathbf{C O O H} \\
{[25,140]{ }^{\circ} \mathrm{C},} \\
{[2,200] \mathrm{kPa}}\end{array}$ & $\begin{array}{c}2.070_{6} \\
\mathbf{a}\end{array}$ & $\begin{array}{c}52.38_{0} \\
\mathrm{a}\end{array}$ & $\begin{array}{c}-47.26 \\
\text { a }\end{array}$ & $\begin{array}{c}4.1_{00} \\
\text { b }\end{array}$ & $\begin{array}{c}64.16 \\
\text { b }\end{array}$ & $\begin{array}{c}10.37 \\
28\end{array}$ & $32.59_{6}$ & $66.47_{0}$ & $33.96_{3}$ & 65.687 & $0.3 \%$ & $0.3 \%$ & $23.02_{8}$ & 117.89 \\
\hline
\end{tabular}

${ }^{a}$ Determined by comparing Eqs (8) and (15) to experimental data for vapour pressure and vaporization heat (formic acid ${ }^{19-21,37,38}$, acetic acid ${ }^{29-33}$; cf. $^{\text {S2 }}$ for details). ${ }^{\mathbf{b}}$

Determined from the comparison between the equation of state (2) and $p-V_{\mathrm{m}}^{\mathrm{g}} T$ data for formic ${ }^{18,24}$ and acetic ${ }^{23-27}$ acids. ${ }^{\mathbf{c}}$ From Eqs (16) and (12). ${ }^{\mathbf{d}}$ Average deviation of Eqs (8) and (15) from the experimental data in the considered $T$ range (cf. $\mathrm{S} 2$ for definition and the text for the data sources). ${ }^{\mathbf{e}}$ Vaporization heat at $25{ }^{\circ} \mathrm{C}$ calculated via Eq (8) (note that $\Delta_{\mathrm{v}} H^{\ominus}$ and $\Delta_{\mathrm{v}} H\left(T^{\ominus}\right)$ differ, as $\Delta_{\mathrm{v}} H^{\ominus}=\Delta_{\mathrm{v}} H_{1}\left(T^{\ominus}\right)$ ). ${ }^{\mathrm{f}}$ Normal boiling temperature, obtained as solution to $p(T)=101325$ Pa, with $p$ given by Eq $(15)$. 
Table 2: Parameters of Kirchhoff's equation (20) for the pressure of vapours forming linear associates.

\begin{tabular}{|c|c|c|c|c|c|c|c|c|c|c|c|c|}
\hline $\begin{array}{l}\text { compound } \\
\text { range }\end{array}$ & $\begin{array}{c}p^{\ominus} \\
\mathrm{kPa}\end{array}$ & $\begin{array}{c}\Delta_{\mathrm{v}} H^{\ominus} \\
\mathrm{kJ} / \mathrm{mol}\end{array}$ & $\begin{array}{c}\Delta_{\mathrm{v}} C_{1} \\
\mathrm{~J} / \mathrm{molK}\end{array}$ & $\begin{array}{l}\ln K_{\mathrm{d}}^{\ominus} \\
/[\mathrm{Pa}]\end{array}$ & $\begin{array}{c}\Delta_{\mathrm{d}} H^{\ominus} \\
\mathrm{kJ} / \mathrm{mol}\end{array}$ & $\begin{array}{c}\Delta_{\mathrm{d}} C \\
\mathrm{~J} / \mathrm{molK}\end{array}$ & $\begin{array}{c}A_{1} \\
\mathrm{f}\end{array}$ & $\begin{array}{c}E_{1} \\
\mathrm{~kJ} / \mathrm{mol}^{\mathrm{f}}\end{array}$ & $\underset{\mathrm{g}}{\operatorname{dev} p}$ & $\underset{\mathrm{g}}{\operatorname{dev} \Delta_{\mathrm{v}} H}$ & $\begin{array}{l}\Delta_{\mathrm{v}} H\left(T^{\ominus}\right) \\
\mathrm{kJ} / \mathrm{mol}^{\mathrm{h}}\end{array}$ & $\begin{array}{l}T_{\mathrm{b}} \\
{ }^{\circ} \mathrm{C}^{\mathrm{i}}\end{array}$ \\
\hline $\begin{array}{c}\mathbf{C H}_{3} \mathbf{O H} \\
{[15,130]{ }^{\circ} \mathrm{C},} \\
{[10,850] \mathrm{kPa}}\end{array}$ & $\begin{array}{c}16.9 \\
34\end{array}$ & $\begin{array}{l}37.96 \\
34,35-\mathbf{b}\end{array}$ & $\begin{array}{c}-37 \\
35\end{array}$ & $\begin{array}{c}13.84 \\
\text { d }\end{array}$ & $\begin{array}{c}17.29 \\
\text { d }\end{array}$ & $\begin{array}{c}0 \\
\text { (neglected) }\end{array}$ & $29.48_{0}$ & $48.98_{6}$ & $0.6 \%$ & $1.5 \%$ & $37.67_{4}$ & 64.67 \\
\hline $\begin{array}{c}\mathbf{C}_{2} \mathbf{H}_{5} \mathbf{O H} \\
{[0,125]^{\circ} \mathrm{C}} \\
{[1,500] \mathrm{kPa}}\end{array}$ & $\begin{array}{c}7.89 \\
34\end{array}$ & $\begin{array}{l}42.34 \\
34,35-\mathbf{b}\end{array}$ & $\begin{array}{c}-46.7 \\
35\end{array}$ & $\underset{d}{13.65}$ & $\underset{\text { d }}{17.29}$ & $\begin{array}{c}0 \\
\text { (neglected) }\end{array}$ & $31.66_{0}$ & $56.26_{2}$ & $0.6 \%$ & $0.6 \%$ & $42.18_{1}$ & 78.39 \\
\hline $\begin{array}{c}\mathbf{C}_{3} \mathbf{H}_{7} \mathbf{O H} \\
{[20,105]{ }^{\circ} \mathrm{C},} \\
{[2,130] \mathrm{kPa}}\end{array}$ & $\underset{\mathrm{a}}{2.833_{4}}$ & $\underset{\mathrm{a}}{47.1_{35}}$ & $\begin{array}{c}-58.3 \\
35\end{array}$ & $\underset{\text { d }}{13.47}$ & $\underset{\mathbf{d}}{17.29}$ & $\begin{array}{c}0 \\
\text { (neglected) }\end{array}$ & $33.97_{1}$ & $64.51_{7}$ & $0.7 \%$ & $1.7 \%$ & $47.06_{6}$ & 96.97 \\
\hline $\begin{array}{c}\mathbf{C}_{4} \mathbf{H}_{9} \mathbf{O H} \\
{[0,125]{ }^{\circ} \mathrm{C},} \\
{[0.1,130] \mathrm{kPa}}\end{array}$ & $\underset{\mathrm{a}}{0.955_{9}}$ & $\underset{\mathrm{a}}{51.3_{50}}$ & $\begin{array}{c}-68.63 \\
c\end{array}$ & $\begin{array}{c}13.29 \\
\text { d }\end{array}$ & $\begin{array}{c}17.29 \\
\text { d }\end{array}$ & $\begin{array}{c}0 \\
\text { (neglected) }\end{array}$ & $35.83_{0}$ & $71.81_{1}$ & $0.6 \%$ & $2.1 \%$ & $51.32_{2}$ & 117.61 \\
\hline $\begin{array}{c}\mathbf{H}_{2} \mathbf{O} \\
{[0,150]{ }^{\circ} \mathrm{C},} \\
{[0.5,450] \mathrm{kPa}}\end{array}$ & $\begin{array}{c}3.169 \\
35\end{array}$ & $\begin{array}{c}43.990 \\
35\end{array}$ & $\begin{array}{c}-41.7 \\
35\end{array}$ & $\begin{array}{c}14.5_{4} \\
\mathrm{e}\end{array}$ & $\begin{array}{c}14.91 \\
\mathbf{e}\end{array}$ & $\begin{array}{c}-0.88 \\
\mathbf{e}\end{array}$ & $30.82_{0}$ & $56.42_{3}$ & $0.4 \%$ & $0.2 \%$ & $43.96_{0}$ & 100.28 \\
\hline $\begin{array}{c}\mathbf{C}_{6} \mathbf{H}_{5} \mathbf{C H}_{3} \\
{[0,135]{ }^{\circ} \mathrm{C}} \\
{[1,200] \mathrm{kPa}}\end{array}$ & $\underset{\mathrm{a}}{3.80_{4}}$ & $\begin{array}{l}38.07 \\
34,35-\mathbf{b}\end{array}$ & $\begin{array}{c}-50.7 \\
35,70\end{array}$ & $\underset{\mathrm{e}}{13.6_{2}}$ & $\underset{\text { e }}{12.6}$ & $\begin{array}{c}0 \\
\text { (neglected) }\end{array}$ & $29.69_{4}$ & $53.18_{5}$ & $0.3 \%$ & $0.3 \%$ & $38.01_{6}$ & 110.64 \\
\hline $\begin{array}{c}\mathbf{C 6}_{6} \mathbf{H}_{6} \\
{[11,166]^{\circ} \mathrm{C},} \\
{[6,841] \mathrm{kPa}}\end{array}$ & $\begin{array}{c}12.7 \\
34\end{array}$ & $\begin{array}{c}33.93 \\
34\end{array}$ & $\begin{array}{c}-53.6 \\
35\end{array}$ & $\begin{array}{c}14.29 \\
\text { e }\end{array}$ & $\underset{\text { e }}{10.47}$ & $\begin{array}{c}0 \\
\text { (neglected) }\end{array}$ & 29.623 & $50.03_{2}$ & $0.9 \%$ & $0.7 \%$ & 33.969 & 80.06 \\
\hline 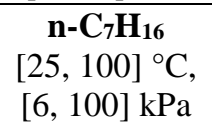 & $\begin{array}{l}6.10 \\
34,35\end{array}$ & $\begin{array}{l}36.64 \\
34,35-\mathbf{b}\end{array}$ & $\begin{array}{c}-55.4 \\
35,70\end{array}$ & $\underset{\mathrm{e}}{13.5_{1}}$ & $\underset{\mathrm{e}}{13.2}$ & $\begin{array}{c}0 \\
\text { (neglected) }\end{array}$ & $30.15_{4}$ & $53.16_{5}$ & $0.14 \%$ & $0.4 \%$ & $36.53_{6}$ & 98.45 \\
\hline $\begin{array}{c}\mathbf{i}-\mathbf{C}_{\mathbf{8}} \mathbf{H}_{18} \\
{[25,100]{ }^{\circ} \mathrm{C},} \\
{[6,100] \mathrm{kPa}} \\
\end{array}$ & $\begin{array}{c}6.50 \\
34\end{array}$ & $\begin{array}{l}35.26 \\
34,35-\mathbf{b}\end{array}$ & $\begin{array}{c}-48.2 \\
34,70\end{array}$ & $\underset{\mathbf{e}}{13.1_{3}}$ & $\begin{array}{c}13.95 \\
\mathbf{e}\end{array}$ & $\begin{array}{c}0 \\
\text { (neglected) }\end{array}$ & $28.78_{7}$ & 49.629 & $0.7 \%$ & - & $35.08_{6}$ & 98.98 \\
\hline
\end{tabular}

a Determined by comparing Eqs (20) and (18) to experimental data for vapour pressure and vaporization heat of propanol [Refs], butanol [Refs] and toluene ${ }^{69,71}$; cf. S3 and S5 for details. ${ }^{\mathbf{b}}$ An average value of two sources ${ }^{34,35}$; Marcus ${ }^{34}$ cites only the value of $\Delta_{\mathrm{v}} H\left(T^{\ominus}\right)-$ Eq (18) is used to calculate the respective $\Delta_{\mathrm{v}} H^{\ominus} \equiv \Delta_{\mathrm{v}} H_{1}\left(T^{\ominus}\right) .{ }^{\mathrm{c}}$ To calculate $\Delta_{\mathrm{v}} C_{1}$, we use a linear extrapolation to $n=4$ from the data of the shorter alcohols. ${ }^{\mathbf{d}}$ Obtained by comparison of Eq (14) with data for $B$ for the four alcohols together, with the assumption for $n$-independent $\Delta_{\mathrm{d}} H^{\ominus}, \ln K_{\mathrm{d}}^{\ominus}$ linearly dependent on $n$, and negligible $\Delta_{\mathrm{d}} C$, see $\mathrm{S} 3$ for details. ${ }^{\mathrm{e}}$ Obtained by comparison of Eq (14) with handbook ${ }^{35,42,46}$ data for $B$, see the main text for details $\left(\Delta_{\mathrm{d}} C\right.$ is neglected), except for water where Ref. 60 is used. No data for isooctane was found, and $B$ data for $\mathrm{n}$-octane is used instead. ${ }^{\mathbf{f}}$ From Eqs (16) and (19). ${ }^{\mathbf{g}}$ Average deviation of Eqs (20) and (18) from the experimental data in the considered $T$ range (cf. S2-S3 for definition and the text for the data sources). ${ }^{\mathbf{h}}$ Vaporization heat at $25{ }^{\circ} \mathrm{C}$ calculated via Eq (18). ${ }^{\mathrm{i}}$ Normal boiling temperature, obtained as solution to $p(T)=101325 \mathrm{~Pa}$, with $p$ given by Eq (20). 
Acknowledgements. The authors acknowledge the funding and technical support from BP through the BP International Centre for Advanced Materials (BP-ICAM) which made this research possible. This research is partly funded by the National Research Foundation (NRF), Prime Minister's Office, Singapore under its Campus for Research Excellence and Technological Enterprise (CREATE) programme. J.K.N. thanks Trinity College and the Clarendon Fund of the University of Oxford for a Clarendon-Titley Scholarship.

The publication contains supplementary materials: S1. Theory. S2. Carboxylic acids. S3. Alcohols. S4. Water. S5. Hydrocarbons. S6. Sensitivity analysis. S7. Sample Maple code for the calculation of $p, w_{2}$ and $\Delta_{\mathrm{v}} H$. S8. List of symbols.

\section{References}

(1) Reid, R. C.; Prausnitz, J. M.; Sherwood, T. K. Chapter 6. In The Properties of Gases and Liquids; McGraw-Hill: New York, 1977.

(2) Haggenmacher, J. E. The Heat of Vaporization as a Function of Pressure and Temperature. J. Am. Chem. Soc. 1946, 68 (8), 1633-1634.

(3) Frost, A. A.; Kalkwarf, D. R. A Semi-Empirical Equation for the Vapor Pressure of Liquids as a Function of Temperature. J. Chem. Phys. 1953, 21 (2), 264-267.

(4) Dake, J. M. K. Evaporative Cooling of a Body of Water. Water Resour. Res. 1972, 8 (4), 1087-1091.

(5) Wexler, A. Vapor Pressure Formulation for Water in Range 0 to $100{ }^{\circ} \mathrm{C}$. A Revision. $J$. Res. Natl. Bur. Stand. Sect. A Phys. Chem. 1976, $80 A$ (5 and 6), 775-785.

(6) Henderson-Sellers, B. A New Formula for Latent Heat of Vaporization of Water as a Function of Temperature. Q. J. R. Meteorol. Soc. 1984, 110 (466), 1186-1190.

(7) Antoine, M. C. Tension Des Vapeurs: Nouvelle Relation Entre Les Tensions et Les Températures. C. R. Hebd. Seances Acad. Sci. 1888, 107, 681-684.

(8) Antoine, M. C. Tensions de Diverses Vapeurs. C. R. Hebd. Seances Acad. Sci. 1888, 107, 836-837.

(9) Filippov, V. K.; Balashova, I. M. Convergence of the Virial Expansion for an Associated Gas. Theor. Exp. Chem. 1972, 5 (4), 356-358.

(10) Marek, J. Vapor-Liquid Equilibria in Mixtures Containing an Associating Substance. II. Binary Mixtures of Acetic Acid at Atmospheric Pressure. Collect. Czechoslov. Chem. Commun. 1955, 20 (6), 1490-1502.

(11) Tamir, A.; Dragoescu, C.; Apelblat, A.; Wisniak, J. Heats of Vaporization and VaporLiquid Equilibria in Associated Solutions Containing Formic Acid, Acetic Acid, Propionic Acid and Carbon Tetrachloride. Fluid Phase Equilib. 1983, 10 (1), 9-42.

(12) Gibbs, J. W. On the Equilibrium of Heterogeneous Substances. Trans. Connect. Acad. Arts Sci. 1878, III, 108-248, 343-524.

(13) Woolley, H. W. The Representation of Gas Properties in Terms of Molecular Clusters. J. Chem. Phys. 1953, 21 (2), 236-241.

(14) Prigogine, I.; Defay, R. Eq 11.59; Eq 26.7. In Chemical Thermodynamics; Longmans Green and Co.: London, 1954.

(15) Prigogine, I. Eq 15.3.7. In The Molecular Theory of Solutions; North-Holland Publishing Company: Amsterdam, 1957.

(16) Togeas, J. B. Acetic Acid Vapor: 2. A Statistical Mechanical Critique of Vapor Density Experiments. J. Phys. Chem. A 2005, 109 (24), 5438-5444.

(17) Mathews, D. M.; Sheets, R. W. Effect of Surface Adsorption on the Determination by Infrared Spectroscopy of Hydrogen Bond Energies in Carboxylic Acid Dimers. J. Chem. Soc. A Inorganic, Phys. Theor. 1969, 2203-2306. 
(18) Coolidge, A. S. The Vapor Density and Some Other Properties of Formic Acid. J. Am. Chem. Soc. 1928, 50 (8), 2166-2178.

(19) Coolidge, A. S. The Vapor Pressure and Heats of Fusion and Vaporization of Formic Acid. J. Am. Chem. Soc. 1930, 52 (5), 1874-1887.

(20) Ambrose, D.; Ghiassee, N. . Vapour Pressures and Critical Temperatures and Critical Pressures of Some Alkanoic Acids: $\mathrm{C}_{1}$ to $\mathrm{C}_{10}$. J. Chem. Thermodyn. 1987, 19 (5), 505519.

(21) Stout, J. W.; Fisher, L. H. The Entropy of Formic Acid. The Heat Capacity from 15 to $300^{\circ} \mathrm{K}$. Heats of Fusion and Vaporization. J. Chem. Phys. 1941, 9 (2), 163-168.

(22) Faubel, M.; Kisters, T. Non-Equilibrium Molecular Evaporation of Carboxylic Acid Dimers. Nature 1989, 339 (6225), 527-529.

(23) Johnson, E. W.; Nash, L. K. The Vapor-Phase Association of Acetic and Trimethylacetic Acids. J. Am. Chem. Soc. 1950, 72 (1), 547-556.

(24) Barton, J. R.; Hsu, C. C. P-V-T-X Properties of Associated Vapors of Formic and Acetic Acids. J. Chem. Eng. Data 1969, 14 (2), 184-187.

(25) Ritter, H. L.; Simons, J. H. The Molecular State of Acetic Acid Vapor. J. Am. Chem. Soc. 1945, 67 (5), 757-762.

(26) Taylor, M. D. The Vapor Phase Dissociation of Some Carboxylic Acids. I. Acetic Acid. J. Am. Chem. Soc. 1951, 73 (1), 315-317.

(27) Gibbs, J. W. On the Vapor-Densities of Peroxide of Nitrogen, Formic Acid, Acetic Acid, and Perchloride of Phosphorus. Am. J. Sci. 1879, s3-18 (107), 371-387.

(28) Chao, J.; Zwolinski, B. J. Ideal Gas Thermodynamic Properties of Methanoic and Ethanoic Acids. J. Phys. Chem. Ref. Data 1978, 7 (1), 363-377.

(29) MacDougall, F. H. The Molecular State of the Vapor of Acetic Acid at Low Pressures at 25, 30, 35 and $40^{\circ}$. J. Am. Chem. Soc. 1936, 58 (12), 2585-2591.

(30) Potter, A. E.; Ritter, H. L. The Vapor Pressure of Acetic Acid and Acetic- $d_{3}$ Acid- $D$. The Liquid Density of Acetic- $d_{3}$ Acid-D. J. Phys. Chem. 1954, 58 (11), 1040-1042.

(31) McDonald, R. A.; Shrader, S. A.; Stull, D. R. Vapor Pressures and Freezing Points of 30 Organics. J. Chem. Eng. Data 1959, 4 (4), 311-313.

(32) Ambrose, D.; Ellender, J. H.; Sprake, C. H. S.; Townsend, R. Thermodynamic Properties of Organic Oxygen Compounds XLV. The Vapour Pressure of Acetic Acid. J. Chem. Thermodyn. 1977, 9 (8), 735-741.

(33) Muñoz, L. A. L.; Krähenbühl, M. A. Isobaric Vapor Liquid Equilibrium (VLE) Data of the Systems $N$-Butanol + Butyric Acid and N-Butanol + Acetic Acid. J. Chem. Eng. Data 2001, 46 (1), 120-124.

(34) Marcus, Y. The Properties of Solvents; John Wiley \& Sons: Chichester, West Sussex, England, 1998.

(35) CRC Handbook of Chemistry and Physics, 98th ed.; Rumble, J., Ed.; CRC Press: Boca Raton, Florida, 2017.

(36) Brown, J. C. XCV.-A Direct Method for Determing Latent Heat of Evaporation. J. Chem. Soc., Trans. 1903, 83, 987-994.

(37) Taylor, M. D.; Bruton, J. The Vapor Phase Dissociation of Some Carboxylic Acids. II. Formic and Propionic Acids. J. Am. Chem. Soc. 1952, 74 (16), 4151-4152.

(38) Konicek, J.; Wadsö, I. Enthalpies of Vaporization of Organic Compounds. VII. Some Carboxylic Acids. Acta Chem. Scand. 1970, 24, 2612-2616.

(39) Kell, G. S.; McLaurin, G. E. Virial Coefficients of Methanol from 150 to $300^{\circ} \mathrm{C}$ and Polymerization in the Vapor. J. Chem. Phys. 1969, 51 (10), 4345-4352.

(40) Tucker, E. E.; Farnham, S. B.; Christian, S. D. Association of Methanol in Vapor and in N-Hexadecane. A Model for the Association of Alcohols. J. Phys. Chem. 1969, 73 (11), 3820-3829. 
(41) Berman, N. S. Hydrogen Bonding in Alcohols. AIChE J. 1968, 14 (3), 497-499.

(42) Kogan, V. B.; Fridman, V. M.; Kafarov, V. V. Page 70. In Equilibrium between liquids and vapours, Vol. 1. (in Russian); Nauka: Moscow-Leningrad, 1966.

(43) Markuzin, N. P.; Baidin, V. N. Second Virial Coefficients and Some Thermodynamic Functions of Saturated Vapors of Chloroform, Hexane, Ethanol, and Their Mixtures at $35^{\circ}$ C. Vestn. Leningr. Univ. 1973, 2, 77-82.

(44) Abusleme, J. A.; Vera, J. H. Pure Compound and Cross Second Virial Coefficients for N-Amylamine-alcohol Systems at $363.15 \mathrm{~K}$. Measurements with a Low Pressure Burnett-Type Apparatus. Fluid Phase Equilib. 1989, 45 (2-3), 287-302.

(45) Foz Gazulla, O. R.; Morcilla, J.; Perez Masia, A.; Mendez, A. . An. R. Soc. Esp. Fis. Quim, Ser. B 1954, 50, 23.

(46) Dymond, J. H.; Marsh, K. N.; Wilhoit, R. C.; Wong, K. C. Virial Coefficients of Pure Gases and Mixtures, Subvolume A: Virial Coefficients of Pure Gases; Frenkel, M., Marsh, K. N., Eds.; Springer-Verlag: Berlin, 2002.

(47) Goodwin, R. D. Methanol Thermodynamic Properties From 176 to $673 \mathrm{~K}$ at Pressures to 700 Bar. J. Phys. Chem. Ref. Data 1987, 16 (4), 799-892.

(48) Ambrose, D.; Sprake, C. H. .; Townsend, R. Thermodynamic Properties of Organic Oxygen Compounds XXXVII. Vapour Pressures of Methanol, Ethanol, Pentan-1-Ol, and Octan-1-Ol from the Normal Boiling Temperature to the Critical Temperature. $J$. Chem. Thermodyn. 1975, 7 (2), 185-190.

(49) Counsell, J. F.; Lee, D. A. Thermodynamic Properties of Organic Oxygen Compounds 31. Vapour Heat Capacity and Enthalpy of Vaporization of Methanol. J. Chem. Thermodyn. 1973, 5 (4), 583-589.

(50) Hirata, M.; Suda, S.; Onodera, Y. Vapor Pressure of Methanol in High Pressure Regions. Chem. Eng. 1967, 31 (4), 339-342,a1.

(51) Svoboda, V.; Veselý, F.; Holub, R.; Pick, J. Enthalpy Data of Liquids. II. The Dependence of Heats of Vaporization of Methanol, Propanol, Butanol, Cyclohexane, Cyclohexene, and Benzene on Temperature. Collect. Czechoslov. Chem. Commun. 1973, 38 (12), 3539-3543.

(52) Counsell, J. F.; Fenwick, J. O.; Lees, E. B. Thermodynamic Properties of Organic Oxygen Compounds 24. Vapour Heat Capacities and Enthalpies of Vaporization of Ethanol, 2-Methylpropan-1-Ol, and Pentan-1-Ol. J. Chem. Thermodyn. 1970, 2 (3), 367372.

(53) Ambrose, D.; Sprake, C. H. S. Thermodynamic Properties of Organic Oxygen Compounds XXV. Vapour Pressures and Normal Boiling Temperatures of Aliphatic Alcohols. J. Chem. Thermodyn. 1970, 2 (5), 631-645.

(54) Dong, J.-Q.; Lin, R.-S.; Yen, W.-H. Heats of Vaporization and Gaseous Molar Heat Capacities of Ethanol and the Binary Mixture of Ethanol and Benzene. Can. J. Chem. 1988, 66 (4), 783-790.

(55) Ortega, J.; Susial, P.; De Alfonso, C. Isobaric Vapor-Liquid Equilibrium of Methyl Butanoate with Ethanol and 1-Propanol Binary Systems. J. Chem. Eng. Data 1990, 35 (2), 216-219.

(56) Kretschmer, C. B.; Wiebe, R. Liquid-Vapor Equilibrium of Ethanol--Toluene Solutions. J. Am. Chem. Soc. 1949, 71 (5), 1793-1797.

(57) Kemme, H. R.; Kreps, S. I. Vapor Pressure of Primary N-Alkyl Chlorides and Alcohols. J. Chem. Eng. Data 1969, 14 (1), 98-102.

(58) Mathews, J. F.; McKetta, J. J. The Thermodynamic Properties of N-Propyl Alcohol. J. Phys. Chem. 1961, 65 (5), 758-762.

(59) Biddiscombe, D. P.; Collerson, R. R.; Handley, R.; Herington, E. F. G.; Martin, J. F.; Sprake, C. H. S. 364. Thermodynamic Properties of Organic Oxygen Compounds. Part 
VIII. Purification and Vapour Pressures of the Propyl and Butyl Alcohols. J. Chem. Soc. 1963, 1954-1957.

(60) Harvey, A. H.; Lemmon, E. W. Correlation for the Second Virial Coefficient of Water. J. Phys. Chem. Ref. Data 2004, 33 (1), 369-376.

(61) Osborne, N. S.; Stimson, H. F.; Fiock, E. F.; Ginnings, D. C. The Pressure of Saturated Water Vapor in the Range $100^{\circ}$ to $374^{\circ}$ C. Bur. Stand. J. Res. 1933, 10 (2), 155-188.

(62) Douslin, D. R.; Osborn, A. Pressure Measurements in the 0.01 to 30 Torr Range with an Inclined-Piston Gage. J. Sci. Instrum. 1965, 42 (6), 369-373.

(63) Stimson, H. F. Some Precise Measurements of the Vapor Pressure of Water in the Range from 25 to $100{ }^{\circ}$ C. J. Res. Natl. Bur. Stand. Sect. A Phys. Chem. 1969, 73 A (5), 493496.

(64) Besley, L.; Bottomley, G. A. Vapour Pressure of Normal and Heavy Water from 273.15 to 298.15 K. J. Chem. Thermodyn. 1973, 5 (3), 397-410.

(65) Guildner, L. A.; Johnson, D. P.; Jones, F. E. Vapor Pressure of Water at Its Triple Point: Highly Accurate Value. Science (80-. ). 1976, 191 (4233), 1261-1261.

(66) Kell, G. S.; McLaurin, G. E.; Whalley, E. The PVT Properties of Water V. The Fluid to $1 \mathrm{Kbar}$ at $350-500{ }^{\circ} \mathrm{C}$ and along the Saturation Line from 150 to $350{ }^{\circ} \mathrm{C}$. Philos. Trans. R. Soc. A Math. Phys. Eng. Sci. 1985, 315 (1532), 235-246.

(67) Osborne, N. S.; Stimson, H. F.; Ginnings, D. C. Calorimetric Determination of the Thermodynamic Properties of Saturated Water in Both the Liquid and Gaseous States from 100 to $374^{\circ}$ C. J. Res. Natl. Bur. Stand. (1934). 1937, 18 (4), 389-447.

(68) Osborne, N. S.; Stimson, H. F.; Ginnings, D. C. Measurements of Heat Capacity and Heat of Vaporization of Water in the Range $0^{\circ}$ to $100^{\circ}$ C. J. Res. Natl. Bur. Stand. (1934). 1939, 23 (2), 197-260.

(69) Chirico, R. D.; Steele, W. V. Reconciliation of Calorimetrically and Spectroscopically Derived Thermodynamic Properties at Pressures Greater than 0.1 MPa for Benzene and Methylbenzene: The Importance of the Third Virial Coefficient. Ind. Eng. Chem. Res. 1994, 33 (1), 157-167.

(70) Yaws, C. L. Handbook of Thermodynamic Diagrams, Volumes 2 and 3; Gulf Publishing Company: Houston, Texas, 1996.

(71) Goodwin, R. D. Toluene Thermophysical Properties from 178 to $800 \mathrm{~K}$ at Pressures to 1000 Bar. J. Phys. Chem. Ref. Data 1989, 18 (4), 1565-1636.

(72) Natarajan, G.; Viswanath, D. S. Enthalpy of Vaporization and Vapor Pressure of Benzene, Toluene, P-Xylene, and Tetralin between 1 and 16 Bar. J. Chem. Eng. Data 1985, 30 (2), 137-140.

(73) Deshpande, D. D.; Pandya, M. V. Thermodynamics of Binary Solutions. Part 2.Vapour Pressures and Excess Free Energies of Aniline Solutions. Trans. Faraday Soc. 1967, 63, 2149-2157.

(74) Willingham, C. B.; Taylor, W. J.; Pignocco, J. M.; Rossini, F. D. Vapor Pressures and Boiling Points of Some Paraffin, Alkylcyclopentane, Alkylcyclohexane, and Alkylbenzene Hydrocarbons. J. Res. Natl. Bur. Stand. (1934). 1945, 35, 219-244.

(75) Forziati, A. F.; Norris, W. R.; Rossini, F. D. Vapor Pressures and Boiling Points of Sixty API-NBS Hydrocarbons. J. Res. Natl. Bur. Stand. (1934). 1949, 43 (6), 555-563.

(76) Mita, I.; Imai, I.; Kambe, H. Determination of Heat of Mixing and Heat of Vaporization with a Differential Scanning Calorimeter. Thermochim. Acta 1971, 2 (4), 337-344.

(77) Waddington, G.; Todd, S. S.; Huffman, H. M. An Improved Flow Calorimeter. Experimental Vapor Heat Capacities and Heats of Vaporization of N-Heptane and 2,2,3Trimethylbutane 1. J. Am. Chem. Soc. 1947, 69 (1), 22-30.

(78) Michou-Saucet, M.-A.; Jose, J.; Michou-Saucet, C.; Merlin, J. C. Pressions de Vapeur et Enthalpies Libres D'exces de Systemes Binaires: Hexamethylphosphorotriamide 
$($ HMPT $)+N$-Hexane; $N$-Heptane; $N$-Octane: A 298,15 K; 303,15 K; 313,15 K; 323,15 K; 333,15 K. Thermochim. Acta 1984, 75 (1-2), 85-106.

(79) Napari, I.; Vehkamäki, H. The Role of Dimers in Evaporation of Small Argon Clusters. J. Chem. Phys. 2004, 121 (2), 819-822.

(80) Counsell, J. F.; Hales, J. L.; Martin, J. F. Thermodynamic Properties of Organic Oxygen Compounds. Part 16.-Butyl Alcohol. Trans. Faraday Soc. 1965, 61, 1869-1875.

TOC graphic:

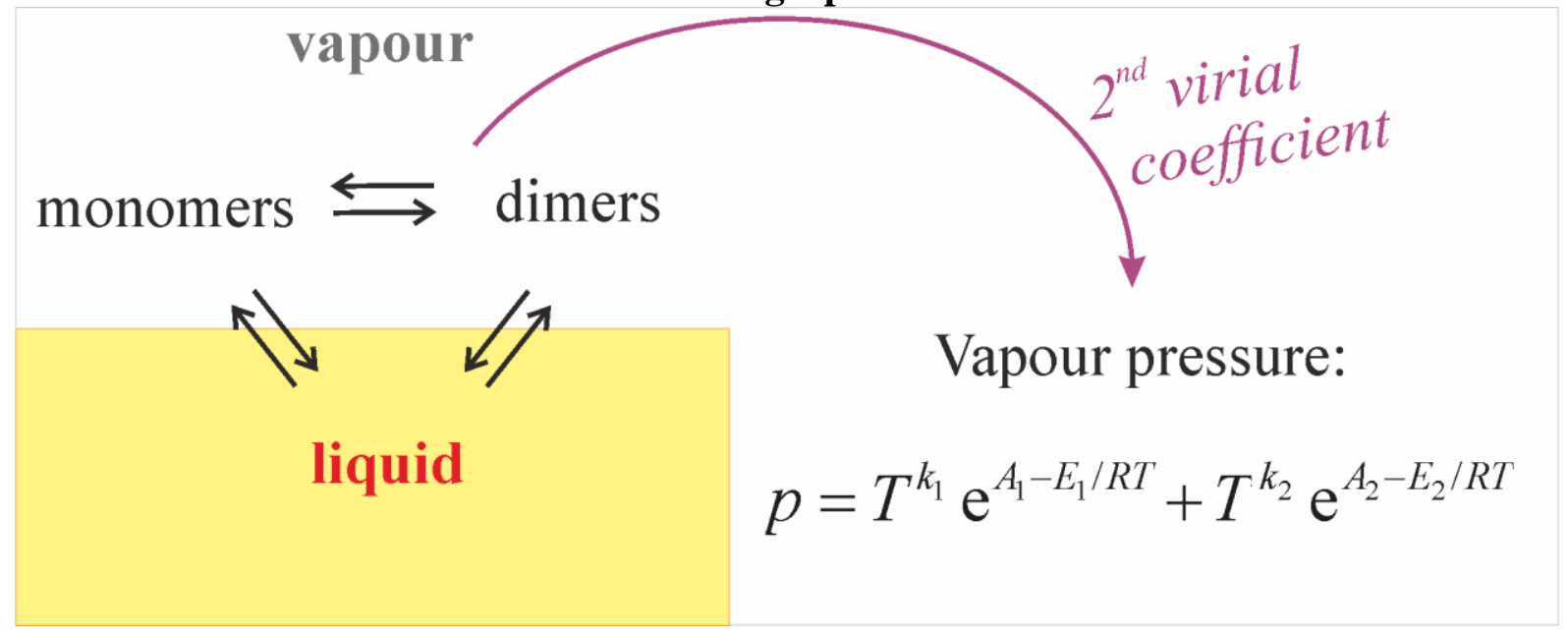




\title{
Vapour pressure and vaporization heat of molecules that associate in the gas phase
}

\author{
Supplementary information
}

\author{
Radomir I. Slavchov ${ }^{1}$, Javor K. Novev ${ }^{2}$, Sebastian Mosbach ${ }^{1}$, Markus Kraft ${ }^{1,3}$ \\ ${ }^{1}$ Department of Chemical Engineering, University of Cambridge, UK \\ ${ }^{2}$ Department of Chemistry, Physical and Theoretical Chemistry Laboratory, University of \\ Oxford, UK \\ ${ }^{2}$ School of Chemical and Biomedical Engineering, Nanyang Technological University, \\ Singapore
}

\section{S1. Theory}

\section{S1-1. The model for linear associates of arbitrary size}

Here, we give a derivation of the equations for $p(T)$ and $\Delta_{\mathrm{v}} H(T)$ for a vapour forming associates of arbitrary length in the gas phase. As follows from Eq (17), the vapour pressure of the $i$-mer can be expressed as

$$
p_{i}=p_{1} p_{i-1} / K_{\mathrm{d}}=p_{1}^{i} / K_{\mathrm{d}}^{i-1}
$$

As in the case with dimers only, the partial pressures of the various associates are related through the mass balance and Dalton's law,

$$
\begin{gathered}
\frac{1}{V_{\mathrm{m}}^{\mathrm{g}}}=\frac{1}{R T} \sum_{i=1}^{\infty} i p_{i}=\frac{K_{\mathrm{d}}}{R T} \sum_{i=1}^{\infty} i\left(\frac{p_{1}}{K_{\mathrm{d}}}\right)^{i}=\frac{p_{1}}{R T}\left(1-\frac{p_{1}}{K_{\mathrm{d}}}\right)^{-2} \text { and } \\
p=\sum_{i=1}^{\infty} p_{i}=K_{\mathrm{d}} \sum_{i}^{\infty}\left(\frac{p_{1}}{K_{\mathrm{d}}}\right)^{i}=p_{1}\left(1-\frac{p_{1}}{K_{\mathrm{d}}}\right)^{-1} .
\end{gathered}
$$

The series in Eqs (22)-(23) are convergent as the model predicts that $p_{1} / K_{\mathrm{d}}<1$, see Eq (24) below. Solving these equations, we obtain for the expressions for the pressure of the monomer

$$
p_{1}=p\left(1+\frac{p}{K_{\mathrm{d}}}\right)^{-1}
$$

and for the molar volume of the gas $V_{\mathrm{m}}^{\mathrm{g}}$,

$$
V_{\mathrm{m}}^{\mathrm{g}}=\frac{R T}{p}\left(1+\frac{p}{K_{\mathrm{d}}}\right)^{-1} .
$$

An equivalent to $\mathrm{Eq}$ (24) for $p_{1}$ has been derived previously in the context of association in alcohols in the liquid phase [Coggeshall, N. D.; Saier, E. L. Infrared Absorption Study of Hydrogen Bonding Equilibria. J. Am. Chem. Soc. 1951, 73 (11), 5414-5418, Prigogine's 
book]. However, to our knowledge, the simple linear association model has not been used in conjunction with the Clausius-Clapeyron equation to determine the vapour pressure of liquids.

Expanding Eq (25) in series about $p=0$, we obtain that the second virial coefficient is identical in form as in the case of dimerization, $B=-R T / K_{\mathrm{d}}$. Furthermore, Eq (24) enables us to calculate the mass fractions of the various associates,

$$
w_{i}=i p_{i} / \sum_{j=1}^{\infty} j p_{j}=i K_{\mathrm{d}}^{2} p^{i-1} /\left(K_{\mathrm{d}}+p\right)^{i+1} .
$$

Having obtained the equation of state (25), we can calculate the fugacity which is, in analogy with Eq (4),

$$
f=p \exp \left[\int_{0}^{p}\left(\frac{V_{\mathrm{m}}^{\mathrm{g}}}{R T}-\frac{1}{p}\right) \mathrm{d} p\right]=K_{\mathrm{d}} y, \text { with } y=\frac{p}{p+K_{\mathrm{d}}},
$$

where $y=p_{2} / p_{1}$. With knowledge of the fugacity, we can proceed to calculate the vaporization enthalpy $\Delta_{\mathrm{v}} H$ of the liquid from the Gibbs-Helmholtz equation, thus obtaining the result (18). Then, we substitute $\Delta_{\mathrm{v}} H$ in the Clausius-Clapeyron relation (9) using that $V_{\mathrm{m}}^{1} / V_{\mathrm{m}}^{\mathrm{g}}<<1$ as before. In full analogy with the case with only dimers present, we can express $p$ through $y$, the ratio between pressures of the dimers and monomers, as given by Eq (27). It is easy to show that $y$ still obeys Eqs (10) and (13) in the case of linear associates. Expressing back $p$ through $y$, we reach the final result (20) for the vapour pressure of a liquid whose vapours form associates of arbitrary length.

\section{S1-2. The relation between the graph representation of the virial expansion and the associate equilibrium representation}

The equivalency between the virial expansion and association equilibrium approach to imperfect gases has been studied by Woolley [HW Woolley. The representation of gas properties in terms of molecular clusters. J. Chem. Phys. 21 (1953) 236-241] and earlier, for dimers only, but in greater detail, by Hirschfelder et al. [http://dx.doi.org/10.1063/1.1723708]. The relations of Woolley between his association constants and the $2-4^{\text {th }}$ virial coefficients can be written in terms of our dissociation constants as:

$$
B=-\frac{R T}{K_{\mathrm{d} 2}}, \quad B_{3}=\frac{4 R^{2} T^{2}}{K_{\mathrm{d} 2}^{2}}-\frac{2 R^{2} T^{2}}{K_{\mathrm{d} 2} K_{\mathrm{d} 3}}, \quad B_{4}=-\frac{20 R^{3} T^{3}}{K_{\mathrm{d} 2}^{3}}+\frac{18 R^{3} T^{3}}{K_{\mathrm{d} 2}^{2} K_{\mathrm{d} 3}}-\frac{3 R^{3} T^{3}}{K_{\mathrm{d} 2} K_{\mathrm{d} 3} K_{\mathrm{d} 4}} .
$$

It is noteworthy that the dissociation constants are more closely related to the $b_{n}$-virial coefficients of the pressure with respect to activity (eqs 12-13 and 12-16 of McQuarrie [DA McQuarrie, Statistical mechanics, Harper and Row, 1976]):

$$
b_{2}=\frac{R T}{K_{\mathrm{d} 2}}, \quad b_{3}=\frac{R^{2} T^{2}}{K_{\mathrm{d} 2} K_{\mathrm{d} 3}} .
$$

This equivalency can be used to give a strict definition of an associate, which is interesting with its analogy to the Gibbs excess formalism widely used in the theory of adsorption. Consider 1 "central" molecule inside a gas of "unperturbed" concentration $c_{1}$. The molecules in the gas do not interact with each other, but interact with the central one with a centrosymmetric potential $u(r)$. This leads to an average concentration $c(r)$ of molecules nearby the central one increased over the unperturbed one with the Boltzmann factor, $c(r)=c_{1} \exp \left(-u(r) / k_{\mathrm{B}} T\right)$. This means that nearby the central molecule, there is an excess of $\Gamma$ gas molecules given by

$$
\Gamma=\int\left(c(r)-c_{1}\right) \mathrm{d} \boldsymbol{r}=c_{1} W, \text { where } W=\int\left(\mathrm{e}^{-u / k_{\mathrm{B}} T}-1\right) \mathrm{d} \boldsymbol{r} .
$$

We use the symbol $\Gamma$, as this quantity is nothing else but the Gibbs excess (Gibbs adsorption on a point) of gas molecules onto the central one. $\Gamma$ is the chance to find an adsorbed molecule 
onto the central one (treated as an adsorption site). We limit ourselves to the case where the gas is dilute so that $\Gamma<<1$ (otherwise, "polyadsorption", i.e. formation of higher aggregates will occur). We define a dimer as a site with an adsorbed gas molecule.

Since all gas molecules, not just the central one, can be such an "adsorption centre", we find that the concentration of dimers is

$$
c_{2}=\Gamma c_{1} / 2=W c_{1}^{2} / 2 ;
$$

here, the factor $1 / 2$ corrects for the fact that each dimer is counted twice, once when each of the molecules is "central". Comparing Eq (31) to Eq (1), we find that

$$
K_{\mathrm{d} 2}=2 R T / W \text {. }
$$

On the other hand, from $\mathrm{Eq}$ (30) and the well-known micromechanical expression $B=-1 / 2 \int\left(\mathrm{e}^{-u / k_{\mathrm{B}} T}-1\right) \mathrm{d} \boldsymbol{r}$ it follows that

$$
B=-W / 2 \text {, and so } K_{\mathrm{d} 2}=-R T / B_{2} .
$$

This is an alternative derivation of $\mathrm{Eq}(6)$.

This "excess" definition can be directly extended to n-mers; it is easily modified for the case where the repulsive forces become comparable to the attractive ones (which is important at high temperatures), and for the case of non-centrosymmetric interaction potential, following the reasoning of Hirschfelder et al. [http://dx.doi.org/10.1063/1.1723708]. Also, the relation (29) seems to provide the key to relate the association representation to the graph technique used for the computation of the virial coefficients. However, these extensions will lead to results fully equivalent to the standard virial expansion, and are anyway well beyond the goals of this work.

In the cases of dimerization $\left(K_{\mathrm{d} 3}=K_{\mathrm{d} 4}=\ldots=\infty\right)$ and linear association $\left(K_{\mathrm{d} 2}=K_{\mathrm{d} 3}=\ldots=\right.$ $K_{\mathrm{d}}$ ), the results of Woolley [Ref] simplify to

$$
\begin{array}{ll}
\text { dimerization: } & B=-\frac{R T}{K_{\mathrm{d}}} ; \quad B_{3}=\frac{4 R^{2} T^{2}}{K_{\mathrm{d}}^{2}} ; \quad B_{4}=-\frac{20 R^{3} T^{3}}{K_{\mathrm{d}}^{3}} ; \\
\text { linear association: } & B=-\frac{R T}{K_{\mathrm{d}}}, \quad B_{3}=\frac{2 R^{2} T^{2}}{K_{\mathrm{d}}^{2}}, \quad B_{4}=-\frac{5 R^{3} T^{3}}{K_{\mathrm{d}}^{3}} .
\end{array}
$$

This means that we can make a simple test of the two models using data for the $3^{\text {rd }}$ virial coefficient. Unfortunately, we have found that the existing data collections for $B_{3}$ are extremely inaccurate, especially for polar and large molecules such as the ones we consider (we find even the order of magnitude and the sign of the published $B_{3}$ spurious). For acetic acids, we compute $B_{3}$ from $p-V_{\mathrm{m}}^{\mathrm{g}}-T$ ourselves to check the validity of Eq (34) in the following supplement. The only gas of those we consider for which the data for $B_{3}$ is of acceptable precision is water. The data for $B_{3}$ shows that in the considered temperature interval, $B_{3}$ of water is large and negative. This means that the assumption that $K_{\mathrm{d} 3}=K_{\mathrm{d} 2}$ seriously underestimates the stability of the trimers, and actually $K_{\mathrm{d} 3}<<K_{\mathrm{d} 2}$. This is easy to understand considering the most probable structure of the dimer and the trimer. The dimer has a single hydrogen bond, so the equilibrium $\mathrm{A}_{2}=2 \mathrm{~A}$ corresponds to the breakage of one such bond. On the other hand, the trimer will obviously have a ring structure with 3 bonds:

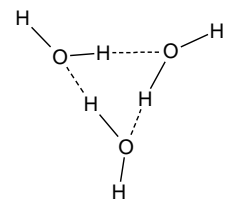

so the equilibrium $\mathrm{A}_{3}=\mathrm{A}_{2}+\mathrm{A}$ corresponds to 2 broken bonds and smaller $K_{\mathrm{d} 3}$. Similar reasoning should hold for the alcohols, and to a smaller extent - to alkanes. Arenes, with their tendency to form stack structures [http://dx.doi.org/10.1039/C2CP23008A], are probably better represented by Eq (17); this is not obvious, however, from the standard deviations in Table 2. 


\section{S2. Carboxylic acids}

\section{S2-1. The parameters of the dimerization; virial coefficients}

The values of $K_{\mathrm{d}}^{\ominus}$ and $\Delta_{\mathrm{d}} H^{\ominus}$ for the acetic acid are obtained by optimization of the merit function

$$
\operatorname{dev}^{2}\left(K_{\mathrm{d}}^{-}, \Delta_{\mathrm{d}} H^{-}\right)=\frac{1}{N-2} \sum_{i}\left(1-\frac{V_{\mathrm{m}, i}^{\mathrm{g}}}{V_{\mathrm{m}, \mathrm{th}}^{\mathrm{g}}\left(p_{i}, T_{i} ; K_{\mathrm{d}}^{-}, \Delta_{\mathrm{d}} H^{-}\right)}\right)^{2} ;
$$

here, $V_{\mathrm{m}, \mathrm{th}}^{\mathrm{g}}$ is the theoretical molar volume of the gas as given by $\operatorname{Eq}(2) ; p_{i}, V_{\mathrm{m}, i}^{\mathrm{g}}$ and $T_{i}$ are the experimental values from the $i$-th measurement; $N$ is the number of data points (taken from various authors ${ }^{23-27}$ in the range $[10,180]{ }^{\circ} \mathrm{C}$; pressures above $1.5 \mathrm{~atm}$ where ignored to avoid complications from the possible presence of $n$-mers). The theoretical value $\Delta_{\mathrm{d}} C=-10.37$ $\mathrm{J} / \mathrm{molK}^{28}$ has been used for Eq (2). The values of $K_{\mathrm{d}}^{\ominus}$ and $\Delta_{\mathrm{d}} H^{\ominus}$ obtained from the optimization of (36) (cf, Table 1) fix the function $K_{\mathrm{d}}(T)$ through Eq (14). $K_{\mathrm{d}}$ is illustrated in Figure S1-right (line), and compared to values calculated directly from each experimental point $\left\{p_{i}, V_{\mathrm{m}, i}^{\mathrm{g}}, T_{i}\right\}$ as

$$
K_{\mathrm{d}}=4 p\left[\left(\frac{2 p V_{\mathrm{m}}^{\mathrm{g}}}{R T}-1\right)^{-2}-1\right]^{-1}
$$

which follows from Eq (2) (blue dots in Figure S1). The dispersion of the dots around the line is a measure of the accuracy of the equation of state (2) and the formula (14) for $K_{\mathrm{d}}(T)$ : in the range $30-150{ }^{\circ} \mathrm{C}$, its precision is excellent; the systematic deviation below $30{ }^{\circ} \mathrm{C}$ shows that the assumption for constant $\Delta_{\mathrm{d}} C$ fails at low temperatures; on the other hand, the high dispersion above $150{ }^{\circ} \mathrm{C}$ is due to the inaccuracy of Eq (2) in this range and the low sensitivity of the experimental data to $K_{\mathrm{d}}$ at high temperature and low pressures (where the behaviour of the gas is close to ideal).

Figure $\mathrm{S} 1$ also shows $K_{\mathrm{d}}$ values calculated from the $B$ data assembled in Kogan et al. ${ }^{42}$ through Eq (6) (red asterisks). As seen, the $B$ data lead to relatively large error, the reason being that, for acetic acid vapours, the equation of state (2) is more accurate than the virial expansion used to determine the $B$-values in Kogan et al. ${ }^{42}$.

The results for formic acid in Figure $\mathrm{S} 1$ are obtained in the same manner.
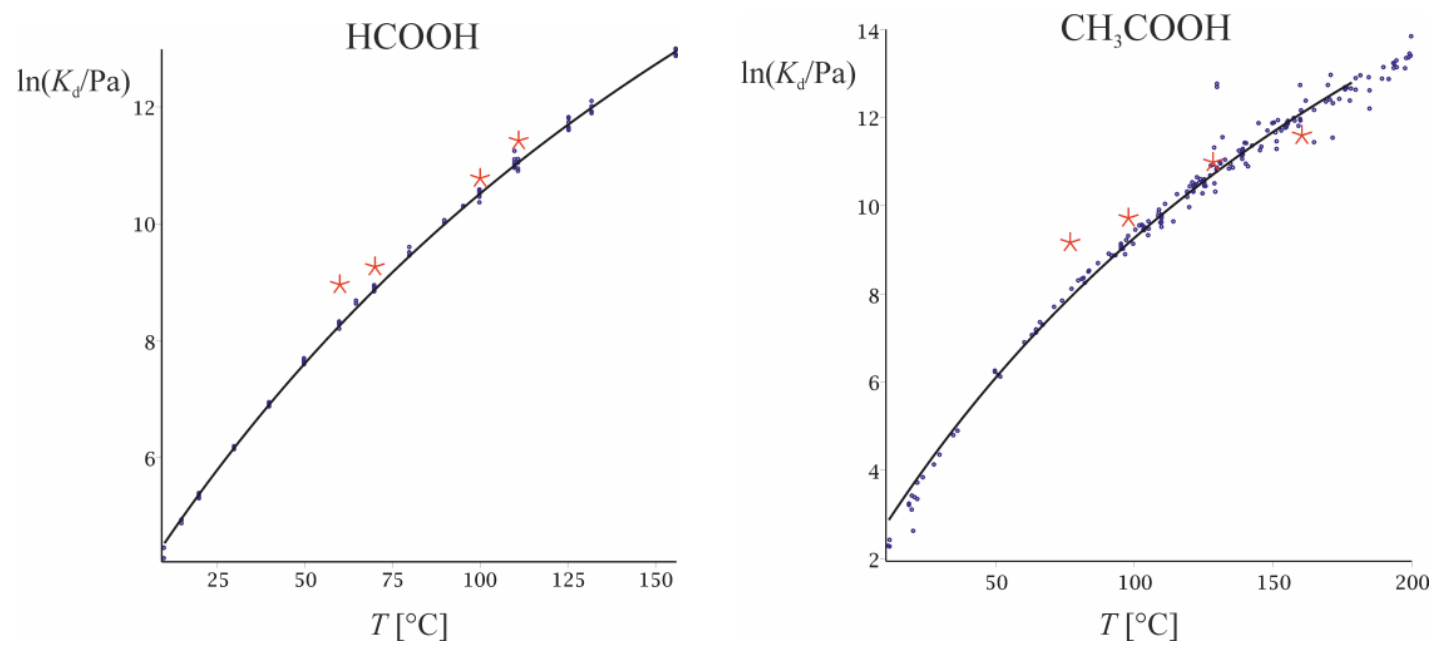

Figure S1. Dissociation constants of formic (left) and acetic (right) acid as functions of the temperature. Lines: Eq (14) with the parameters from Table 1. Blue dots: $K_{\mathrm{d}}$ calculated directly from the $p-V_{\mathrm{m}}^{\mathrm{g}}-T$ data from various authors ${ }^{18,23-27}$ through Eq (37). Red asterisks: $K_{\mathrm{d}}$ computed from $B$ data from Kogan et al. ${ }^{42}$ through Eq (6). 
We further used the $p-V_{\mathrm{m}}^{\mathrm{g}}-T$ for the acetic acid to determine the trimerization constant of it. Assuming that, in addition to $\mathrm{Eq}(1)$, a dissociation equilibrium $\mathrm{A}_{3}=\mathrm{A}_{2}+\mathrm{A}$ is established, one easily reaches at the relations

$$
\frac{1}{V_{\mathrm{m}}^{\mathrm{g}}}=\frac{p_{1}}{R T}\left(1+\frac{2 p_{1}}{K_{\mathrm{d} 2}}+\frac{3 p_{1}^{2}}{K_{\mathrm{d} 2} K_{\mathrm{d} 3}}\right) ; \quad p=p_{1}\left(1+\frac{p_{1}}{K_{\mathrm{d} 2}}+\frac{p_{1}^{2}}{K_{\mathrm{d} 2} K_{\mathrm{d} 3}}\right),
$$

which set parametrically the equation of state of a monomer-dimer-trimer gas. For each experimental $p_{i}, V_{\mathrm{m}, i}^{\mathrm{g}}$ and $T_{i}$ of the acetic acid, we calculate $K_{\mathrm{d} 2}$ as obtained in Figure $\mathrm{S} 1$ (with the parameters in Table 1). This leaves two unknowns in Eqs (38): $p_{1}$ and $K_{\mathrm{d} 3}$. We solve these equations for each experimental point, to obtain the result for $K_{\mathrm{d} 3}$ in Figure S2-left. As seen, for temperatures $<140{ }^{\circ} \mathrm{C}$, the trimers are significantly less stable than the dimers $\left(K_{\mathrm{d} 3}>>K_{\mathrm{d} 2}\right)$. In Figure S2-right, the respective $3^{\text {rd }}$ virial coefficient is given; the red points are those obtained directly from the experimental $p-V_{\mathrm{m}}^{\mathrm{g}}-T$ data and $\mathrm{Eq}$ (28), while the blue line corresponds to dimers only, Eq (34). As seen, the contribution of the trimers is indeed small, due to $K_{\mathrm{d} 3} \gg K_{\mathrm{d} 2}$.

Note that the $3^{\text {rd }}$ virial coefficient we determined differ from those of Dymond et al. [Ref] by many orders of magnitude. It seems that this is because the equation of state we use is better suited for the system than the virial expansion up to the $3^{\text {rd }}$ virial term: the use of the polynomial equation of state tends to produce slightly different $B$ and very different $B_{3}$ values, compensating artificially for the total contribution of the dimers to the higher virial coefficients. This discrepancy can be avoided by using very accurate data for relatively low pressures only; the problem seems to be missing with the water data, but not with the methanol data in Dymond et al. [Ref]. For this reason, we left the monomer-dimer-trimer model for the simpler though less accurate linear association model.
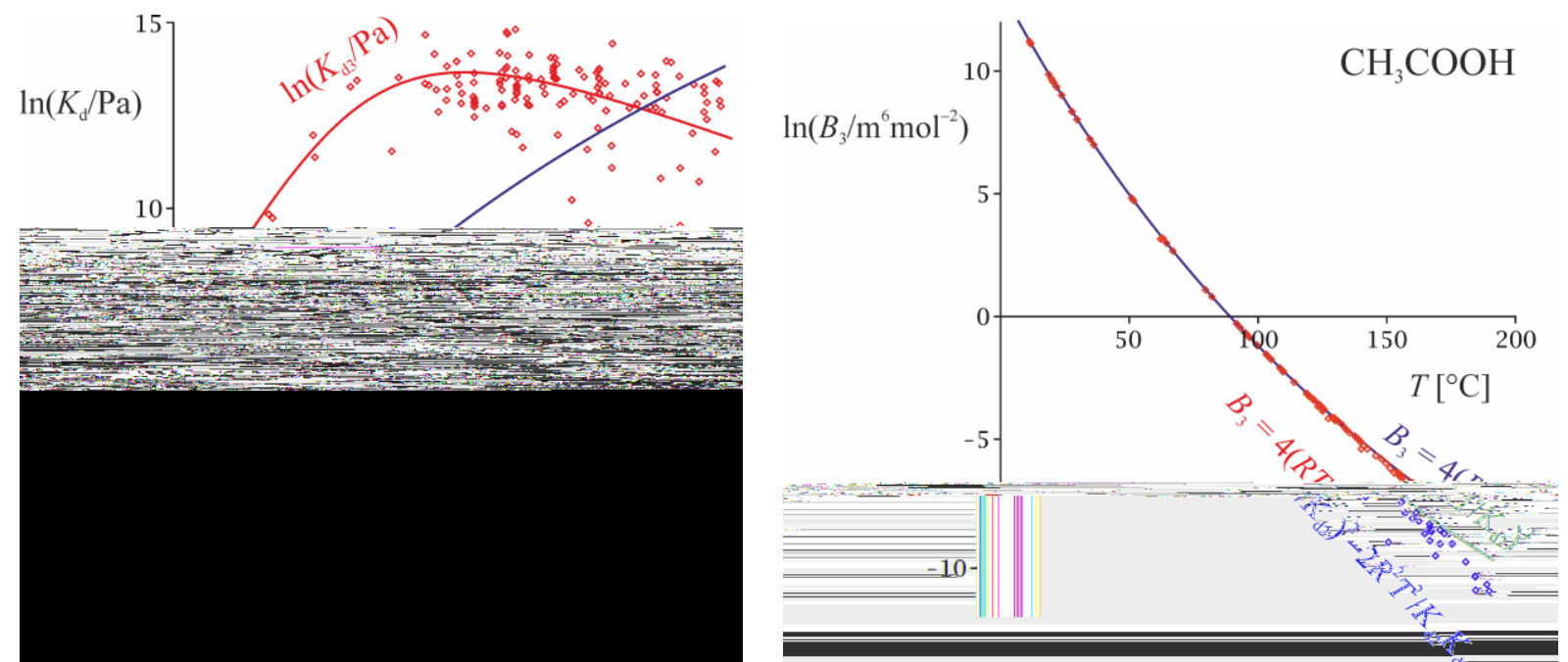

Figure S2. Left: dissociation constants of the dimer (blue) and the trimer (red) of acetic acid as a function of the temperature. Eq (14) with the parameters from Table 1 is used for the dimer dissociation. The red points are obtained from $p-V_{\mathrm{m}}^{\mathrm{g}}-T$ data ${ }^{18,23-27}$ through Eqs (38). The red line is to guide the eye. Right: the respective $3^{\text {rd }}$ virial coefficient, calculated from each of the points on the left figure through Eq (28). The blue line corresponds to $B_{3}$ with trimerization ignored, Eq (34). For temperatures up to $140{ }^{\circ} \mathrm{C}$, the trimerization has a negligible effect on $B_{3}$. 


\section{S2-2. The parameters of evaporation}

The other three parameters of the model $\left(p^{\ominus}, \Delta_{\mathrm{v}} H_{1}^{\ominus}\right.$ and $\left.\Delta_{\mathrm{V}} C_{1}\right)$ have been obtained by comparing the theoretical expressions Eqs (15) and (8) (indicated with subscript "th") to experimental data for the vapour pressure $\left(p_{i}\right)$ and for the vaporization heat $\left(h_{\mathrm{e}, j}\right)$, via the optimization of the merit function

$$
\begin{aligned}
& \operatorname{dev}_{p, H}^{2}\left(p^{\star}, \Delta_{\mathrm{v}} H_{1}^{\star}, \Delta_{\mathrm{v}} C_{1}\right)= \\
& \left.\frac{1}{N 3} \Gamma_{i} 1 \frac{p_{\mathrm{th}}\left(T_{i} ; p^{-}, \Delta_{\mathrm{v}} H_{1}^{-}, \Delta_{\mathrm{v}} C_{1}\right)^{2}}{p_{i}}{ }_{j} \quad 1 \frac{\Delta_{\mathrm{v}} H_{\mathrm{th}}\left(T_{j} ; p^{-}, \Delta_{\mathrm{v}} H_{1}^{-}, \Delta_{\mathrm{v}} C_{1}\right)}{\Delta_{\mathrm{v}} H_{j}}{ }^{2}\right\rceil
\end{aligned}
$$

In the case of formic acid, the data for the vapour pressure and the vaporization heat are optimized together, by minimizing $d e v^{2}$ from Eq (39). For the acetic acid, only the vapour pressure data have been optimized ( $d e v^{2}$ without the second sum in the square brackets). The results are illustrated and compared to the data in Figure S3 (vapour pressure) and Figure S4 (vaporization heat and weight fraction of the dimer).
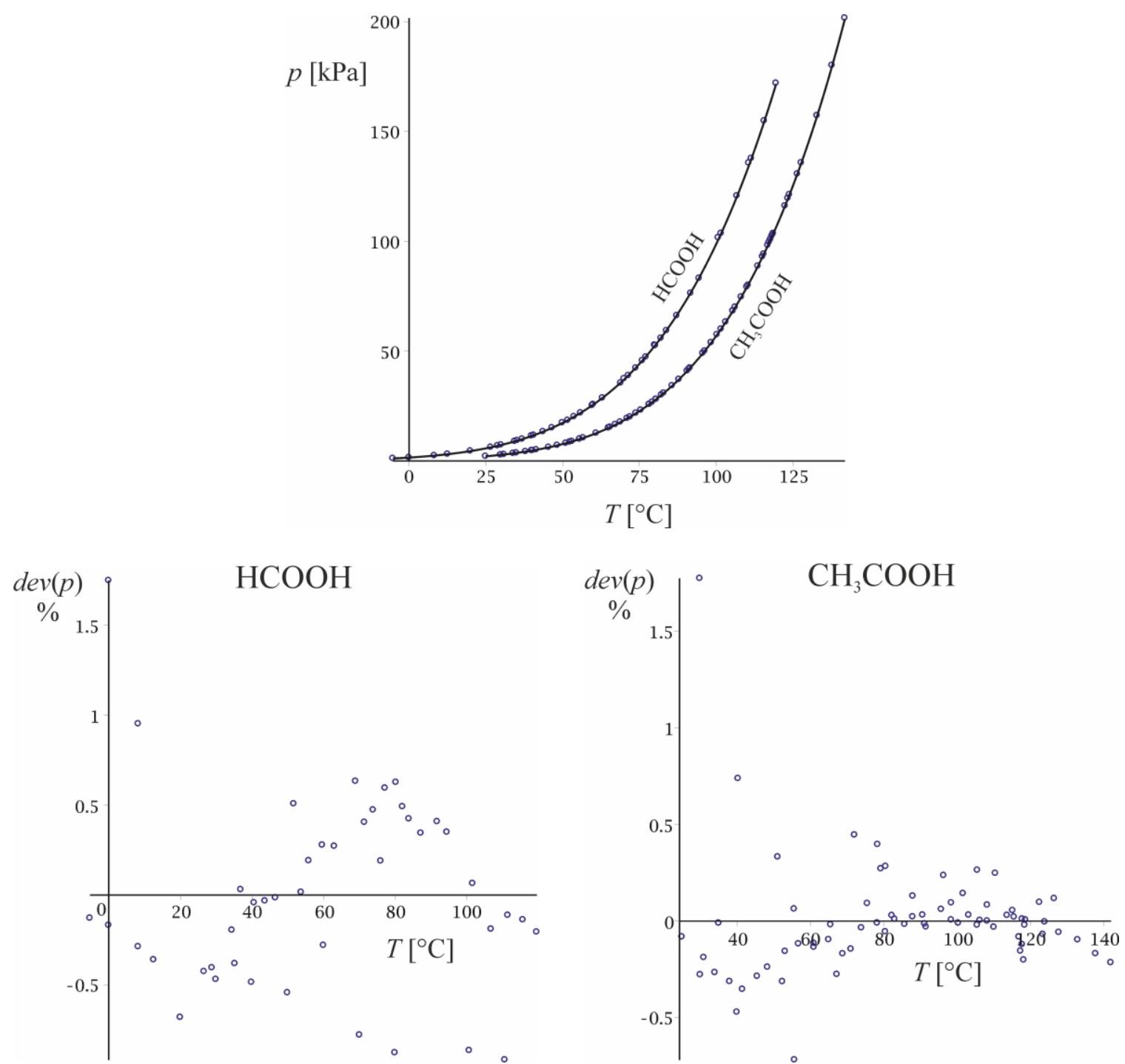

Figure S3. Up: vapour pressure of $\mathrm{HCOOH}$ and $\mathrm{CH}_{3} \mathrm{COOH}$ vs. temperature. Lines: $\mathrm{Eq}(15)$ with the parameters from Table 1. Dots: experimental data from different authors ${ }^{19,20,29-33,37}$. Down: \% deviation between theory and experimental points. 

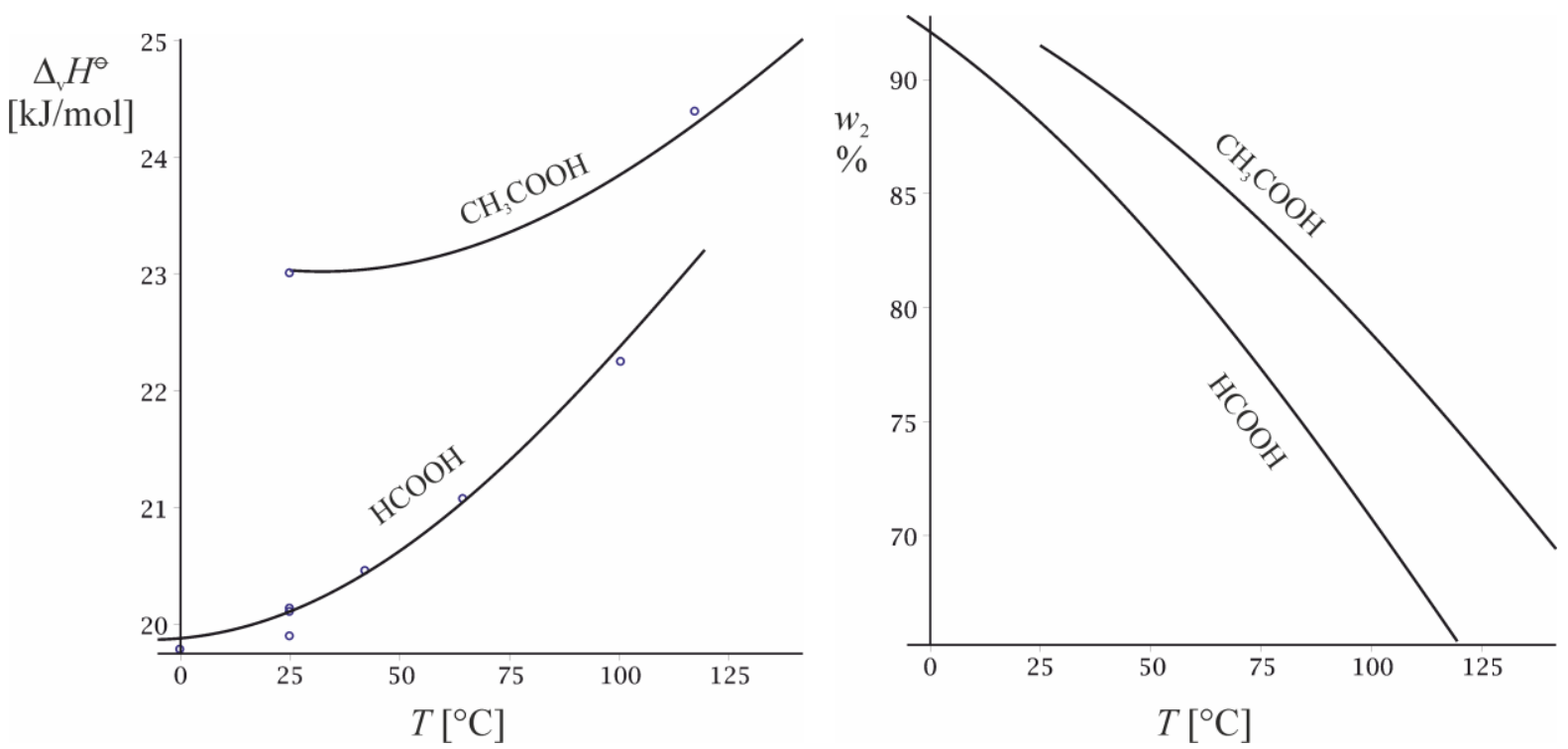

Figure S4. Heat of evaporation (left, Eq (8)) and weight fraction of carboxylic acid dimers in the saturated vapours (right, $\mathrm{Eq}(5)$ ) as a function of the temperature. Data are from various sources $^{19,21,34,36,38}$.

The respective standard deviations reported in Table $\mathbf{1}$ are

$$
\operatorname{dev}_{p}=\sqrt{\frac{\sum_{i}\left(1-p_{\mathrm{th}}\left(T_{i}\right) / p_{i}\right)^{2}}{N_{p}-3 \frac{N_{p}}{N_{H}+N_{p}}}}, \quad d e v_{h}=\sqrt{\frac{\sum_{j}\left(1-\Delta_{\mathrm{v}} H\left(T_{j}\right) / \Delta_{\mathrm{v}} H_{j}\right)^{2}}{N_{H}-3 \frac{N_{H}}{N_{H}+N_{p}}}},
$$

where $N_{p}$ and $N_{H}$ are the number of experimental points for $p$ and $\Delta_{\mathrm{v}} H$, respectively. The use of such dimensionless deviation is necessary for two reasons: first, it allows data for vaporization heat and vapour pressure to be optimized together, Eq (39), and second, it allows results for the vapour pressure at low and high temperatures to be optimized together (a dimensional merit function would put massive weight on the high temperature results, as there the vapour pressure is several order of magnitudes higher - although the number of valid digits is typically unchanged).

\section{S3. Alcohols}

For normal alkanols from methanol to butanol, we determine the parameters of $K_{\mathrm{d}}(T)$ from a simultaneous fit to data for all four compounds. We assume that the natural logarithm of $K_{\mathrm{d}}^{\ominus}$ follows a linear function of the number of carbon atoms $n, \ln K_{\mathrm{d}}^{\ominus}=\ln K_{\mathrm{d} 0}^{\ominus}+n \Delta \mu_{\mathrm{CH}_{2}}^{\ominus} / R T$. As neither assuming a similar dependence for the standard enthalpy of the dissociation reaction $\Delta_{\mathrm{d}} H^{\ominus}$ (17) nor using the associated heat capacity change $\Delta_{\mathrm{d}} C$ as another free parameter affect the end results for $B$ significantly, we fit data for all alcohols with a single, $n$-independent value of $\Delta_{\mathrm{d}} H^{\ominus}$ and we set $\Delta_{\mathrm{d}} C=0$. We take $B(T)$ data from various sources ${ }^{35,42-45}$, as described in the main text. To obtain $\ln K_{\mathrm{d} 0}^{\ominus}, \Delta \mu_{\mathrm{CH}_{2}}^{\ominus}$ and $\Delta_{\mathrm{d}} H^{\ominus}$, we minimize the merit function 


$$
\operatorname{dev}_{K}^{2}\left(K_{\mathrm{d} 0}^{\ominus}, \Delta_{\mathrm{d}} H^{\ominus}, \Delta \mu_{\mathrm{CH}_{2}}^{\oplus}\right)=\frac{1}{N-3} \sum_{i}\left(1-\frac{K_{\mathrm{d}, \mathrm{th}}\left(T_{i}, n_{i} ; K_{\mathrm{d} 0}^{\ominus}, \Delta_{\mathrm{d}} H^{\ominus}, \Delta \mu_{\mathrm{CH}_{2}}^{\oplus}\right)}{K_{\mathrm{d}, i}}\right)^{2},
$$

where $K_{\mathrm{d}, \text { th }}$ is calculated from $\mathrm{Eq}(14), K_{\mathrm{d}, i}$ is determined from the experimental $B$-values according to Eq (6), $n_{i}$ is the number of carbon atoms in the alcohol referred to in the $i$-th measurement, and $N$ is the total number of measurements for all four alcohols. The best-fit values obtained in this way are $\ln K_{\mathrm{d} 0}^{\ominus} /[\mathrm{Pa}]=14.024, \Delta \mu_{\mathrm{CH}_{2}}^{\ominus} / R T^{\ominus}=-0.18396$ and $\Delta_{\mathrm{d}} H^{\ominus}=$ $17.291 \mathrm{~kJ} / \mathrm{mol}$, corresponding to a deviation of $\operatorname{dev}_{K}=8.5 \%$.

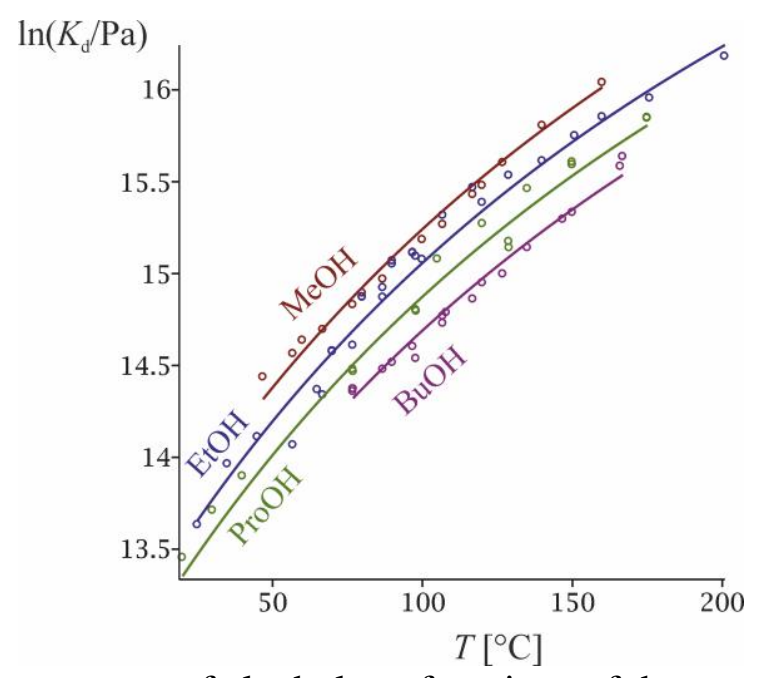

Figure S5. Dissociation constants of alcohols as functions of the temperature. Lines: Eq (14) with the parameters from Table 1, obtained through minimization of Eq (41). Dots: $K_{\mathrm{d}}$ computed from $B$ data da,42-45 $^{35 r o u g h ~ E q ~(6) . ~}$

For methanol and ethanol, we use handbook data for $p^{\ominus}$ and $\Delta_{\mathrm{v}} H_{1}^{\ominus}$, as described in Table 2, whilst for propanol and butanol, we determine these parameters from a fit of the merit function

$$
\begin{aligned}
& \operatorname{dev}_{p, H}^{2}\left(p^{\ominus}, \Delta_{\mathrm{v}} H_{1}^{\ominus}\right)= \\
& \quad \frac{1}{N-2}\left[\sum_{i}\left(1-\frac{p_{\mathrm{th}}\left(T_{i} ; p^{\ominus}, \Delta_{\mathrm{v}} H_{1}^{\ominus}\right)}{p_{i}}\right)^{2}+\sum_{j}\left(1-\frac{\Delta_{\mathrm{v}} H_{\mathrm{th}}\left(T_{j} ; p^{\ominus}, \Delta_{\mathrm{v}} H_{1}^{\ominus}\right)}{\Delta_{\mathrm{v}} H_{j}}\right)^{2}\right]
\end{aligned}
$$

to the experimental data ${ }^{33,51,53,55,57-59,80}$, where $N$ is the total number of considered data-points. The results are illustrated in Figure S6 and Figure S7. 

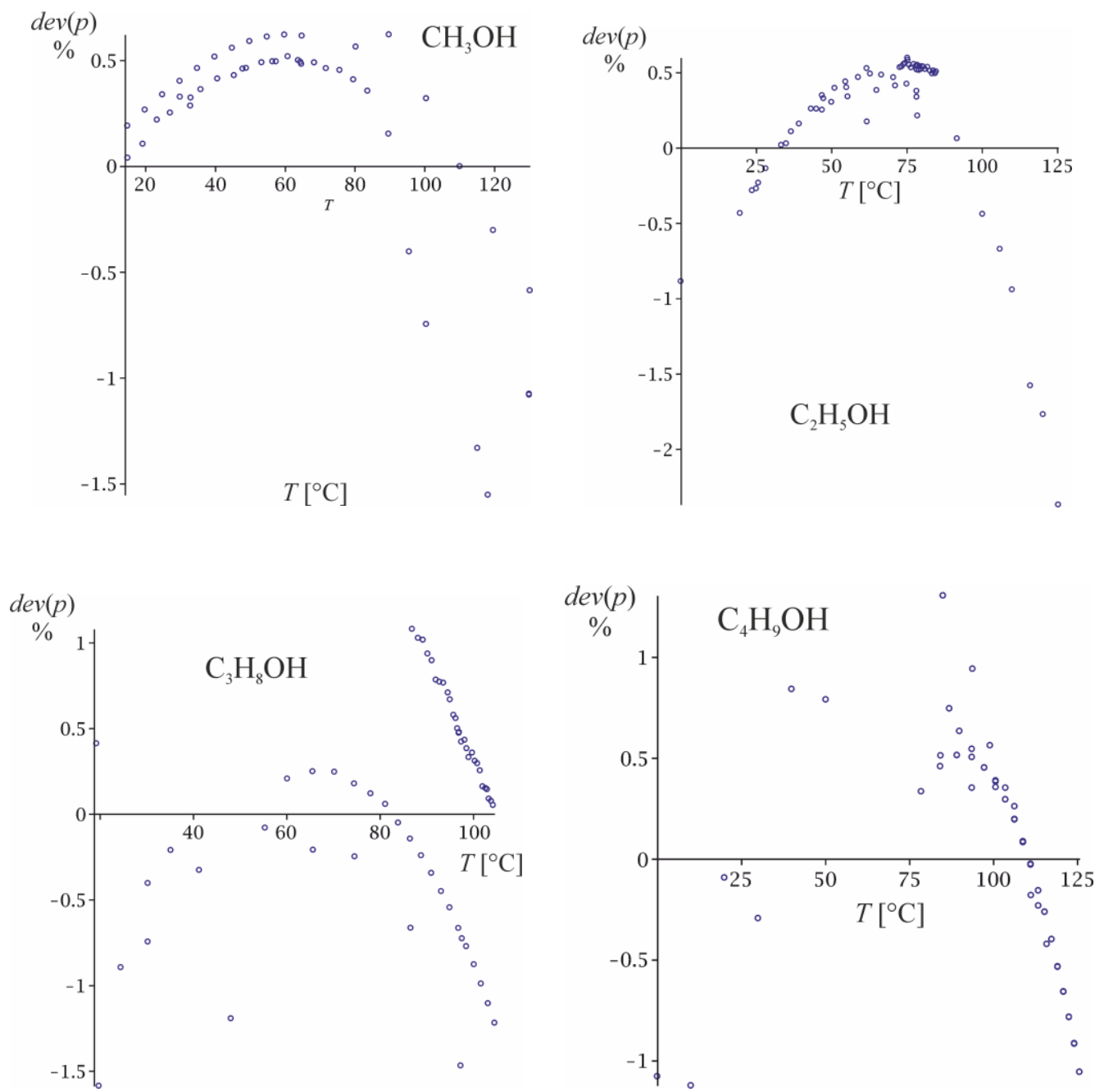

Figure S6. Vapour pressure of alcohols vs. temperature: deviation of Eq (15) with the parameters in Table 2 from the experimental data.
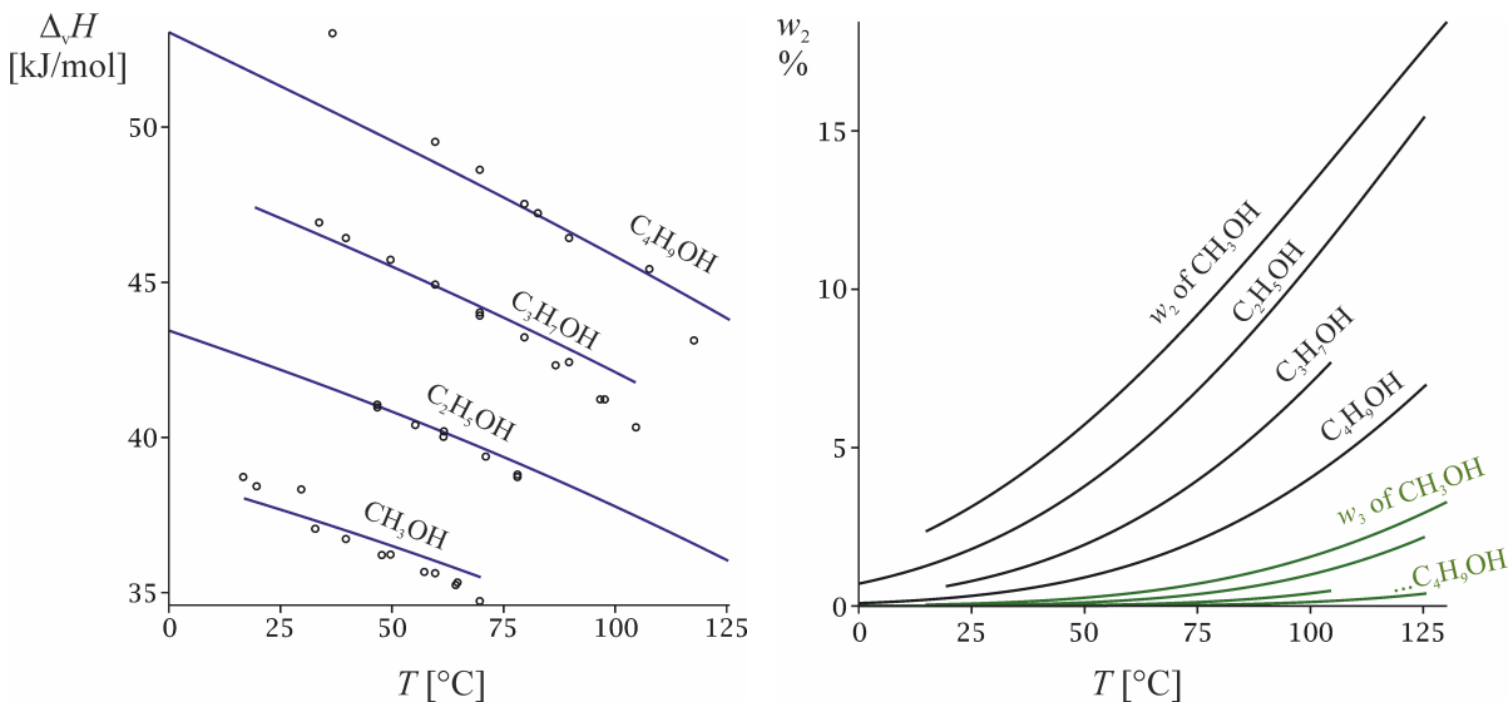

Figure S7. Heat of evaporation (left, Eq (8)) and weight fraction of alcohol dimers in the saturated vapours (right, Eq (5)) as function of the temperature. Data are from Counsell et al. ${ }^{49}$ and Svoboda et al. ${ }^{51}$ (methanol), Counsell et al. ${ }^{52}$ and Dong and Lin $^{54}$ (ethanol). 


\section{S4. Water}

For water, we calculate the dimerization parameters from the second virial coefficient data assembled by Harvey and Lemmon ${ }^{60}$. To obtain the values of $K_{\mathrm{d}}^{\ominus}, \Delta_{\mathrm{d}} H^{\ominus}$, and $\Delta_{\mathrm{d}} C$ in Table 2 , we minimize the merit function

$$
\operatorname{dev}\left(K_{\mathrm{d}}^{\diamond}, \Delta_{\mathrm{d}} H^{\diamond}, \Delta_{\mathrm{d}} C\right)=\frac{1}{200 \mathrm{~K}} \int_{273 \mathrm{~K}}^{473 \mathrm{~K}}\left|B(T)+\frac{R T}{K_{\mathrm{d}, \mathrm{th}}\left(T ; K_{\mathrm{d}}^{\diamond}, \Delta_{\mathrm{d}} H^{\diamond}, \Delta_{\mathrm{d}} C\right)}\right| \mathrm{d} T,
$$

where $B(T)$ is the regression equation of Harvey and Lemmon ${ }^{60}$ and $K_{\mathrm{d} \text {,th }}$ is Kirchhoff's model (14) for the dissociation constant; $-R T / K_{\mathrm{d}, \text { th }}$ is the theoretical $B$, cf. Eq (6). The difference between the two formulae with the parameters in Table 2 is $1-2 \%$ above $150{ }^{\circ} \mathrm{C}$ and less than $0.5 \%$ between 0 and $150{ }^{\circ} \mathrm{C}$. The other parameters are handbook data, as explained in Table 2. The comparison of the model with vapour pressure and vaporization heat data is given in Figure S8 and Figure S9.

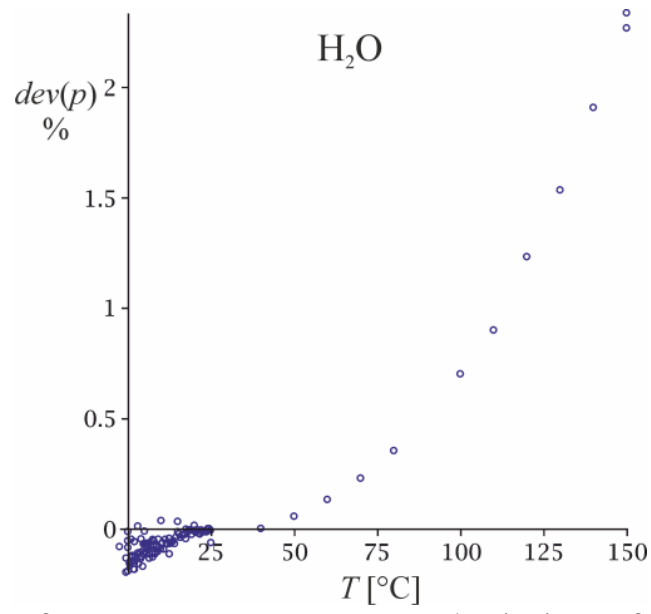

Figure S8. Vapour pressure of water vs. temperature: deviation of Eq (20) with the parameters from Table 2 from the experimental data from various authors ${ }^{61-66}$. At high temperatures, the formula is inaccurate because of the inaccurate trimerization modelling (cf. S2 for details).
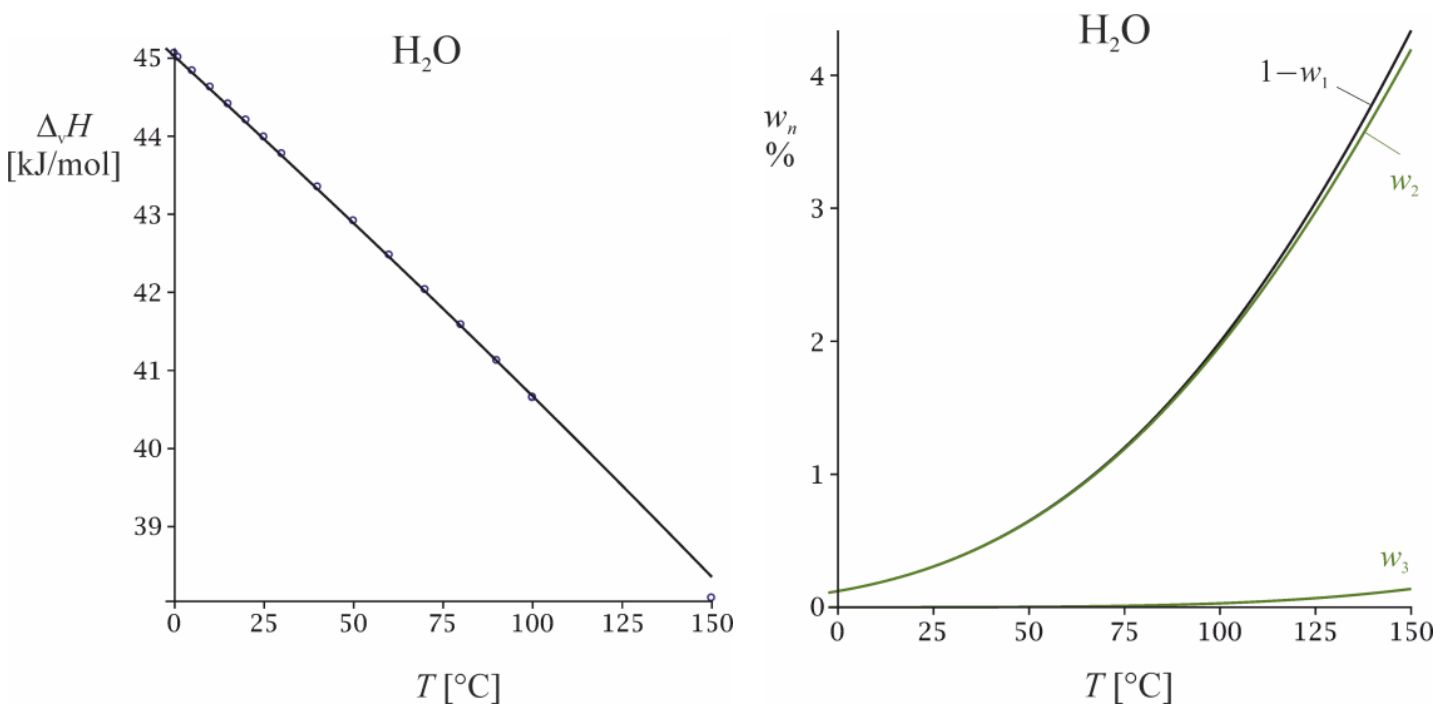

Figure S9. Heat of evaporation (left, Eq (18)) and weight fraction of linear associates (1- $w_{1}-$ total associates, $w_{2}$ - dimers, $w_{3}$ - trimers) in the saturated steam (right, Eq (26)) as functions of the temperature. Data are from Osborne et al. ${ }^{67,68}$. Note that the linear association model underpredicts the trimer fraction in water, cf. S2. 


\section{S5. Hydrocarbons}

The data for hydrocarbons are dealt similarly to those for water. The only exception is toluene: the handbook value of the room temperature vapour pressure $p^{\ominus}$ is found rather inaccurate, and we use the experimental vapour pressure from Chirico and Steele ${ }^{69}$ and Goodwin ${ }^{71}$ and a merit function of the type (39) (but with fixed $\Delta_{\mathrm{V}} H^{\ominus}$ and $\Delta_{\mathrm{V}} C_{1}$ ) to determine it. All results are illustrated in Figure S10 and Figure S11.
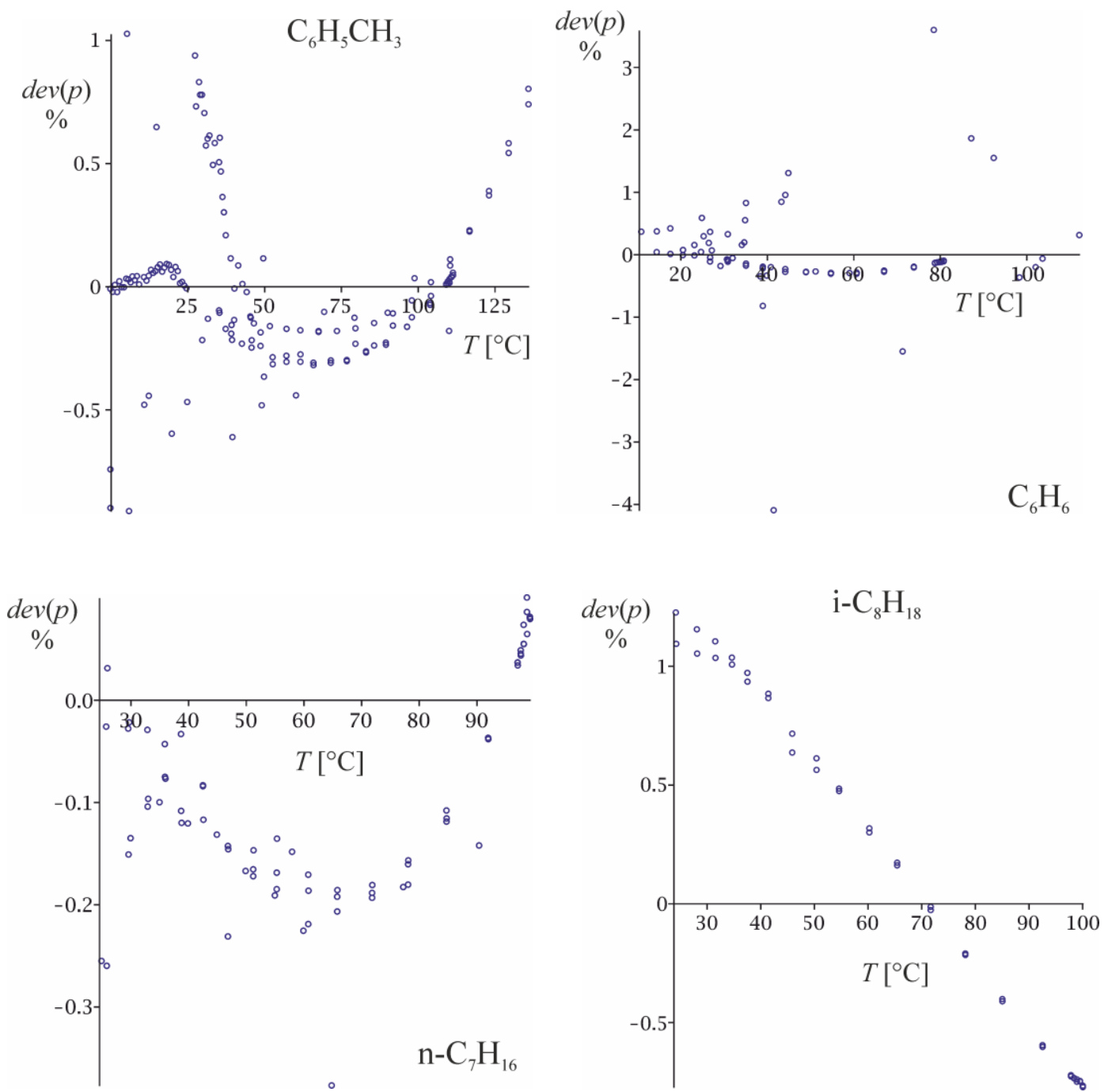

Figure S10. Vapour pressure of toluene, benzene, heptane and isooctane vs. temperature: deviation of Eq (20) with the parameters from Table 2 from the experimental data from various sources ${ }^{35,42,48,52-55}$. 

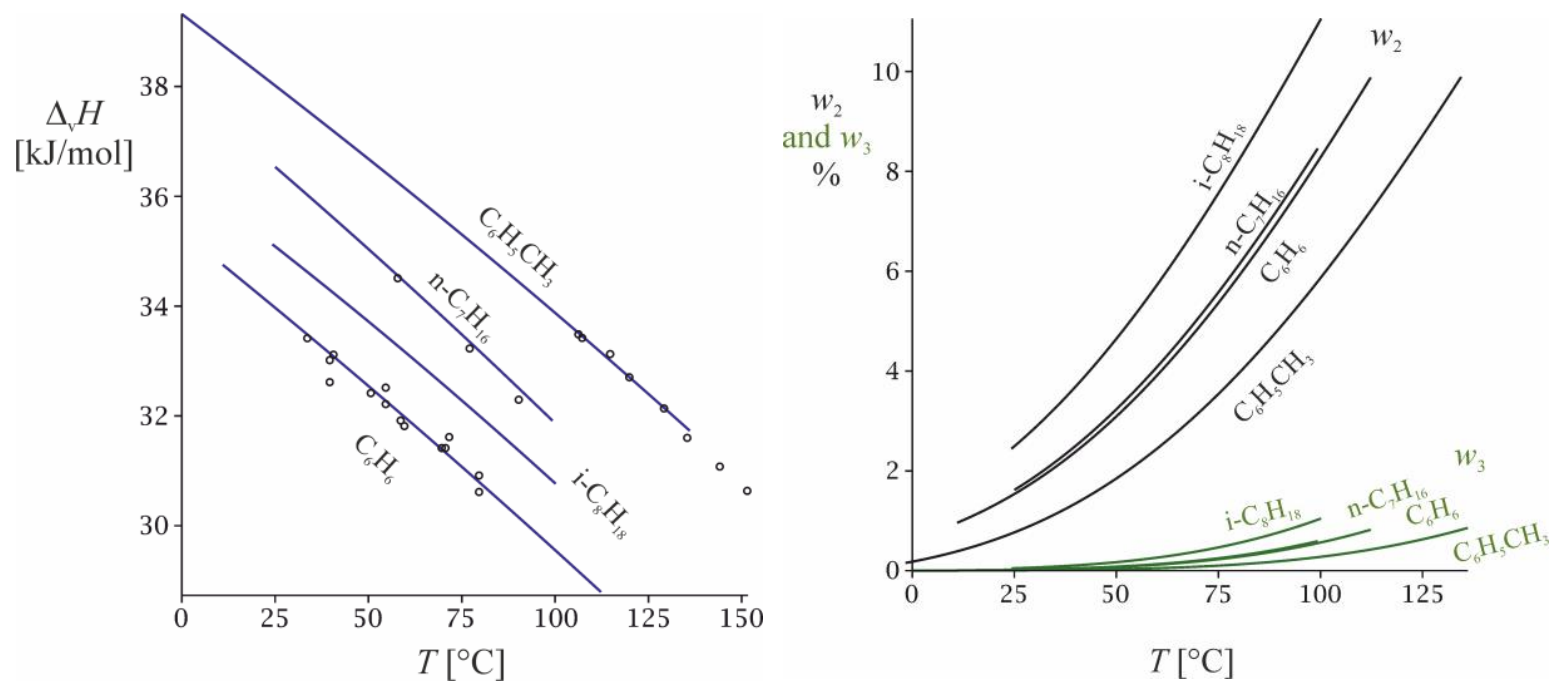

Figure S11. Heat of evaporation (left, Eq (18)) and weight fraction of associates in the saturated vapours (right, Eq (26)) of toluene, benzene, heptane and isooctane as function of the temperature. Data are from Natarajan ${ }^{72}$ and Viswanath and Waddington et al. ${ }^{77}$.

\section{S6. Sensitivity analysis}

The sensitivities of the merit functions (36),(39) and (42) to each parameter can be evaluated using a function of the type

$$
s_{\%}(\delta)=\frac{d e v_{p, H}\left[p_{\mathrm{opt}}^{-}\left(1+10^{-\delta}\right)\right]-2 d e v_{p, H}\left(p_{\mathrm{opt}}^{-}\right)+\operatorname{dev}_{p, H}\left[p_{\mathrm{opt}}^{-}\left(1-10^{-\delta}\right)\right]}{d e v_{p, H}\left(p_{\mathrm{opt}}^{-}\right)} \times 100,
$$

where $p_{\mathrm{opt}}^{\ominus}$ is the value of $p^{\ominus}$ at the minimum of $\operatorname{dev}_{p, H}$ (for the example), and $\delta$ is a "variation" in the $\delta^{\text {th }}$ digit of $p^{\ominus}$. The numerator of $s \%$ is approximately proportional to the second derivative of $d e v_{p, H}$ with respect to $p^{\ominus}, \Delta_{\mathrm{V}} H^{\ominus}$ and $\Delta_{\mathrm{V}} C$ can be similarly varied. The dependence of $s \%$ on the variations of $p^{\ominus}, \Delta_{\mathrm{v}} H^{\ominus}$ and $\Delta_{\mathrm{v}} C$ is illustrated in Figure S12. A value of $s \%=5 \%$ means that the variation of the parameter by $10^{-\delta}$ of its value causes $5 \%$ change of the value of the standard deviation. Assuming that the last sensitive digit is the one that corresponds to $\mathrm{s} \%$ in the range $[0.5,5] \%$, from Figure S12 we find that the $4^{\text {th }}$ digit of $\Delta_{\mathrm{v}} H^{\ominus}$, the $3^{\text {rd }}-4^{\text {th }}$ digit of $p^{\ominus}$, and the $2^{\text {nd }}-$ $3^{\text {rd }}$ digit of $\Delta_{v} C$ still affect the standard deviation. We did a similar analysis for the sensitivity of the dispersion (i.e. of our vapour pressure and vaporization heat formulae) on the other 3 parameters involved: $K_{\mathrm{d}}^{\ominus}, \Delta_{\mathrm{d}} H^{\ominus}$ and $\Delta_{\mathrm{d}} C$; $\operatorname{dev}_{p, H}$ of acids is very sensitive to $\Delta_{\mathrm{d}} H^{\ominus}\left(3^{\text {rd }}-4^{\text {th }}\right.$ digit $)$, less to $K_{\mathrm{d}}^{\ominus}\left(2^{\text {nd }}-3^{\text {rd }}\right.$ digit $)$ and only weakly on $\Delta_{\mathrm{d}} C\left(1^{\text {st }}-2^{\text {nd }}\right.$ digit $)$. This analysis also means that a small error in $\Delta_{\mathrm{v}} H^{\ominus}$ can compensate a large error in $\Delta_{\mathrm{v}} C$, or a massive error in $\Delta_{\mathrm{d}} C$, which makes the values of $\Delta_{\mathrm{v}} C$ in Table 1 and Table 2 unreliable, and makes it impossible $\Delta_{\mathrm{d}} C$ to be used as an adjustable parameter together with $\Delta_{\mathrm{v}} H^{\ominus}$. 


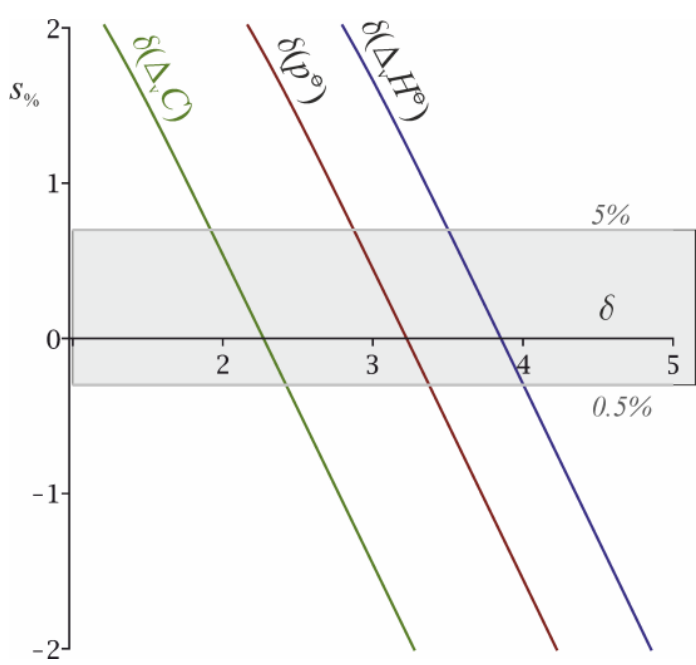

Figure S12. Illustration to the sensitivity analysis with Eq (44).

\section{S7. Sample Maple code for calculation of $p, w_{n}$ and $h_{\mathrm{e}}$}

S8-1. Liquids in equilibrium with vapours containing monomers and dimers

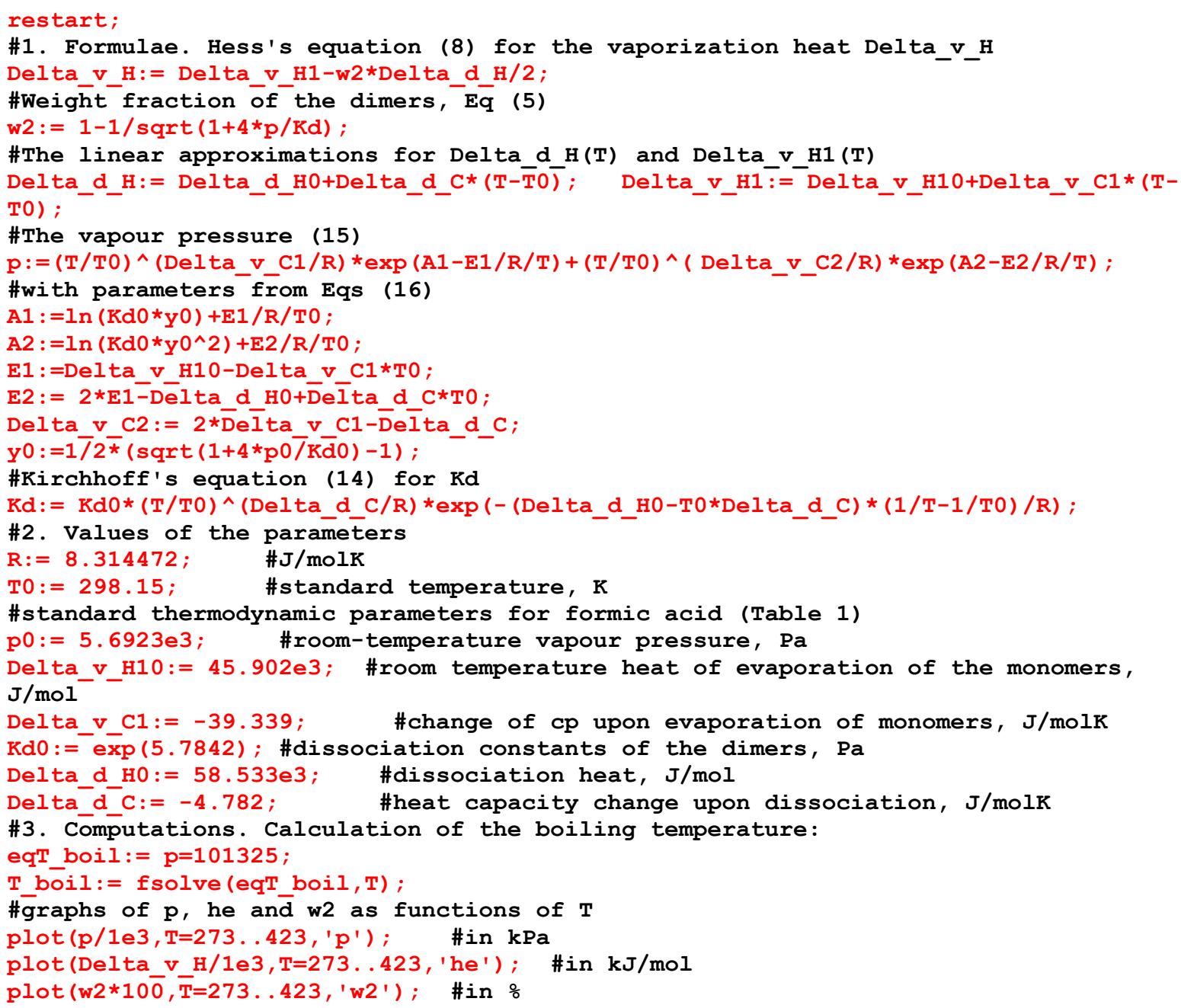




\section{S8-2. Liquids in equilibrium with vapours containing linear associates}

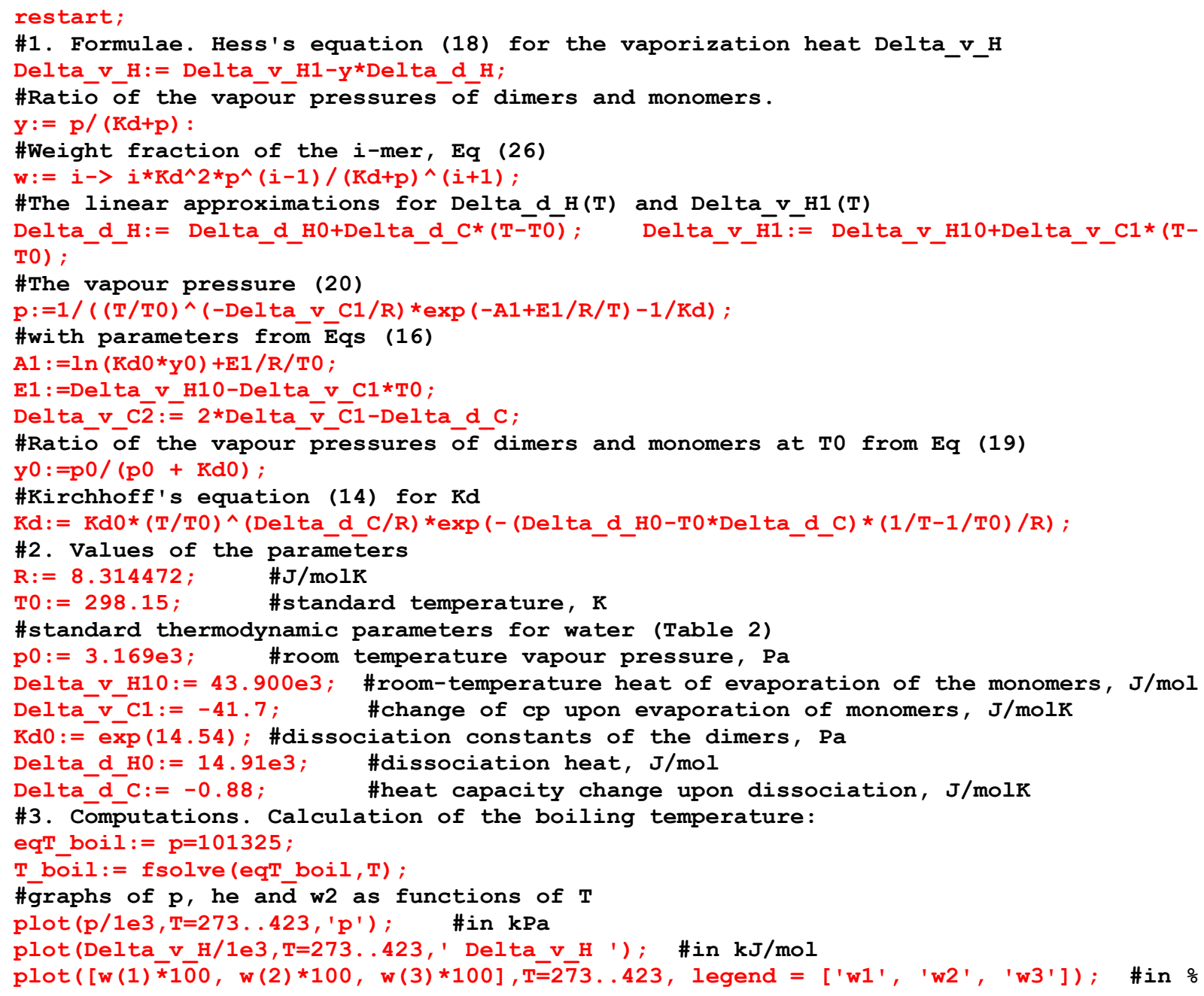

\section{S8. List of symbols}

$B \quad$ second virial coefficient

$C_{1}^{\mathrm{g}}$ and $C_{2}^{\mathrm{g}} \quad$ partial molar heat capacities at constant pressure of the monomer and the dimer in the gas phase

$C_{\mathrm{m}}^{1} \quad$ molar heat capacity of the liquid at constant pressure

$\Delta_{\mathrm{d}} C=2 C_{1}^{\mathrm{g}}-C_{2}^{\mathrm{g}} \quad$ change of heat capacity at constant $p$ per mole yield of the reaction (1) $\Delta_{\mathrm{v}} C_{1}=C_{1}^{\mathrm{g}}-C_{\mathrm{m}}^{1} \quad$ change of the heat capacity upon evaporation of a mole of the monomer $\Delta_{\mathrm{v}} C_{2}=C_{2}^{\mathrm{g}}-2 C_{\mathrm{m}}^{1} \quad$ change of $C$ upon evaporation of a mole of the dimer

$f \quad$ fugacity, Eqs (4) and (27)

$\Delta_{\mathrm{d}} H \quad$ heat of dimer dissociation

$\Delta_{\mathrm{d}} H^{\ominus} \quad \Delta_{\mathrm{d}} H$ at $T^{\ominus}$

$\Delta_{\mathrm{v}} H \quad$ heat of vaporization (for a non-ideal gas) 


$\begin{array}{ll}\Delta_{\mathrm{v}} H^{\ominus} & \Delta_{\mathrm{v}} H \text { at } T^{\ominus} \\ \Delta_{\mathrm{v}} H_{1} & \text { heat of vaporization of monomers }\left(\Delta_{\mathrm{d}} H \text { at } p \rightarrow 0\right) \\ \Delta_{\mathrm{v}} H_{1}^{\ominus} & \Delta_{\mathrm{v}} H_{1} \text { at } T^{\ominus} \\ K_{\mathrm{d}} & \text { dissociation constant of associates in the gas phase, Eqs (1) and (17) } \\ K_{\mathrm{d}}^{\ominus} & \text { value of } K_{\mathrm{d}} \text { at } T^{\ominus} \\ p & \text { pressure, or saturated vapour pressure } \\ p^{\ominus} & \text { vapour pressure at the standard } T^{\ominus} \\ p_{1} \text { and } p_{2} & \text { partial pressures of the monomers and the dimers } \\ R & \text { universal gas constant } \\ T & \text { temperature } \\ T^{\ominus} & \left.\text { standard temperature (25 }{ }^{\circ} \mathrm{C}\right) \\ T_{\mathrm{boiling}} & \text { boiling temperature } \\ V_{\mathrm{m}}^{\mathrm{g}} & \text { molar volume of the gas, Eqs (2) and (25) } \\ V_{\mathrm{m}}^{1} & \text { molar volume of the liquid } \\ X^{\ominus} & \text { value of } X \text { at } T^{\ominus} \\ y & \text { pressure ratio } p_{2} / p_{1}, \text { Eqs (4) and (18) } \\ y^{\ominus} & \text { value of } y \text { at standard pressure and temperature, Eq (12) and (27) } \\ w_{\mathrm{i}} & \text { weight fraction of the monomers and the i-mers in the gas }\end{array}$

